\title{
WestVirginiaUniversity
}

THE RESEARCH REPOSITORY @ WVU

Graduate Theses, Dissertations, and Problem Reports

2014

\section{Lower extremity alignment and back and lower extremity pain during pregnancy}

Kathryn Harrison

West Virginia University

Follow this and additional works at: https://researchrepository.wvu.edu/etd

\section{Recommended Citation}

Harrison, Kathryn, "Lower extremity alignment and back and lower extremity pain during pregnancy" (2014). Graduate Theses, Dissertations, and Problem Reports. 575.

https://researchrepository.wvu.edu/etd/575

This Thesis is protected by copyright and/or related rights. It has been brought to you by the The Research Repository @ WVU with permission from the rights-holder(s). You are free to use this Thesis in any way that is permitted by the copyright and related rights legislation that applies to your use. For other uses you must obtain permission from the rights-holder(s) directly, unless additional rights are indicated by a Creative Commons license in the record and/ or on the work itself. This Thesis has been accepted for inclusion in WVU Graduate Theses, Dissertations, and Problem Reports collection by an authorized administrator of The Research Repository @ WVU. For more information, please contact researchrepository@mail.wvu.edu. 


\title{
LOWER EXTREMITY ALIGNMENT AND BACK AND LOWER EXTREMITY PAIN DURING PREGNANCY
}

Thesis submitted to the college of Health Sciences at West Virginia University in partial fulfillment of the requirements for the degree of Master of Science in Exercise Physiology

\author{
Jean L. McCrory, PhD, Chair \\ Corrie A. Mancinelli, PT, PhD \\ Krystal Thomas, MS, DPT, PT \\ Petronela Meszaros, MD \\ Sergiy Yakovenko, $\mathrm{PhD}$ \\ Division of Exercise Physiology \\ Department of Human Performance and Applied Exercise Science
}

Morgantown, West Virginia

2014

Keywords: Pregnancy, foot, pain 


\title{
ABSTRACT \\ Lower extremity alignment and back and lower extremity pain during pregnancy
}

\author{
Kathryn Harrison
}

Over $50 \%$ of women experience musculoskeletal pain in the low back or lower extremity during pregnancy. Further, $31 \%$ of these women experience continued pain after giving birth. Many women also report changes in foot length and arch height during pregnancy. The purpose of this study was to determine if changes in foot anthropometry during pregnancy are related to low back and lower extremity pain. A secondary aim was to determine if added weight alone explains changes in lower extremity alignment, or if other factors mediate these changes. Methods: Fifteen primigravid women were recruited to participate, along with thirteen weight-matched nulliparous controls. Several measures of foot and lower extremity alignment were assessed during the $1^{\text {st }}, 2^{\text {nd }}$, and $3^{\text {rd }}$ trimesters, as well as post-partum. These measures included: foot length, foot width, arch index, arch height index, arch rigidity index, arch drop, rearfoot angle and pelvic obliquity. Musculoskeletal pain was assessed using a Visual Analogue Scale. Controls and participants who had not yet reached the full weight of pregnancy repeated measurements weighted with a pack worn over the anterior trunk. Results: Over the course of a first pregnancy, significant changes were seen in foot length, arch index and pelvic obliquity. Added weight alone produced significant changes in arch drop and arch rigidity index only. Changes in foot width, standing arch height index and pelvic obliquity were related to pain at the low back, hip and knee during pregnancy. Conclusion: Pregnant women experience changes in lower extremity anthropometry and alignment that may contribute to musculoskeletal pain. 


\section{CONTENTS}

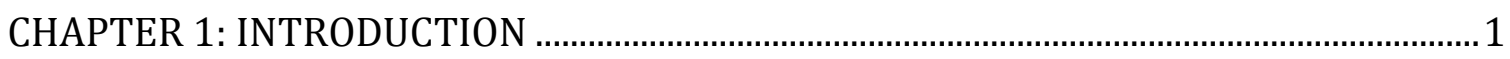

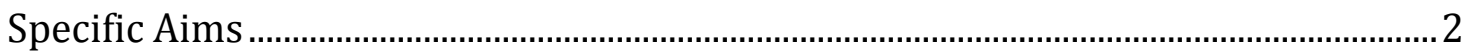

Background And Significance .......................................................................................

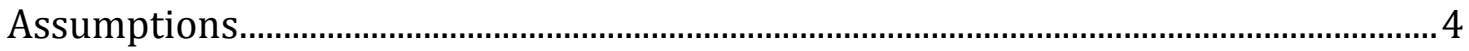

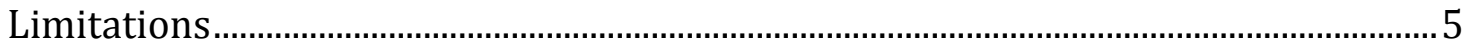

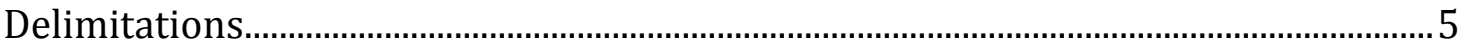

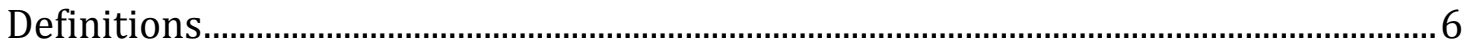

CHAPTER 2: REVIEW OF THE LITERATURE.....................................................................

Pain in Pregnancy …………………………………………………………………..

Bodily Changes During Pregnancy …………………………………………………...

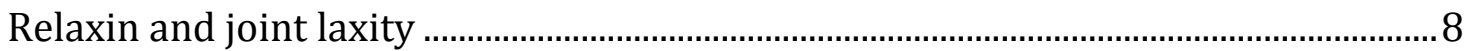

Joint alignment and posture ......................................................................................

Relationship between alignment and back pain .......................................................... 11

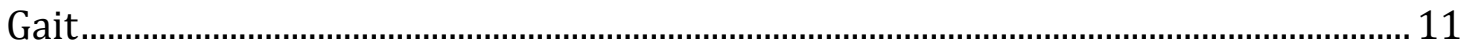

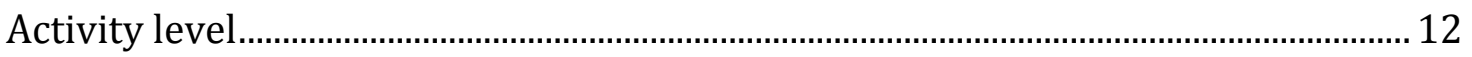

Targeted exercise treatment ....................................................................................... 13

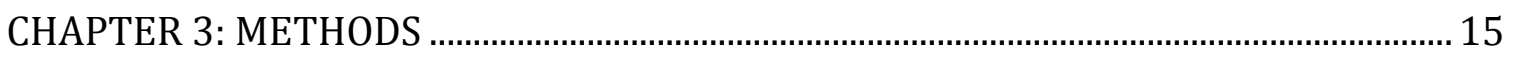

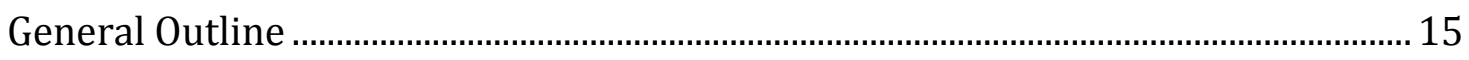

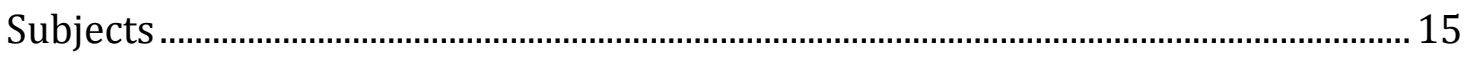

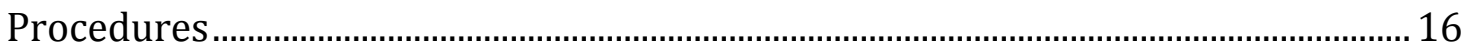

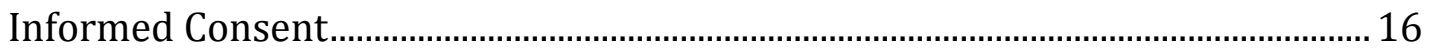

Pain Assessment ................................................................................................... 17

Biomechanical Assessment ......................................................................................... 17

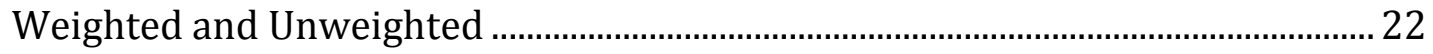

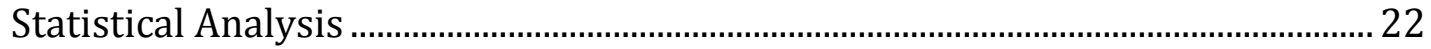

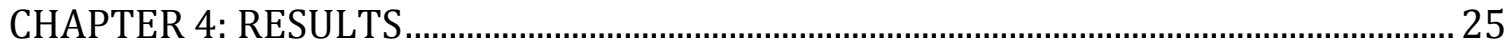

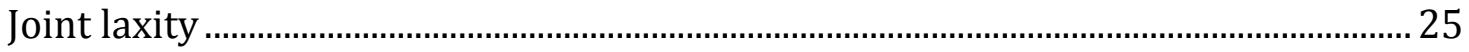

Specific Aim 1: Changes in anthropometry and alignment.......................................... 25

Specific Aim 2: Relationship between anthropometry and alignment changes and

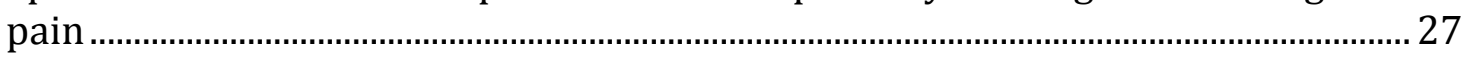

Differences in pain between groups ..................................................................... 28

Correlation between pain and anthropometry/alignment......................................29 
Correlation between changes in anthropometry/alignment and pain 30

Correlation between left/right asymmetry and pain ................................................ 33

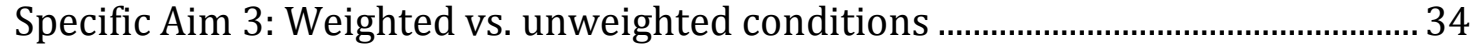

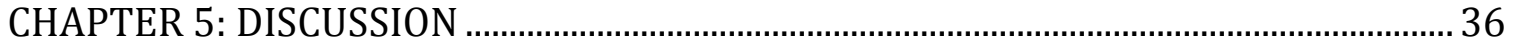

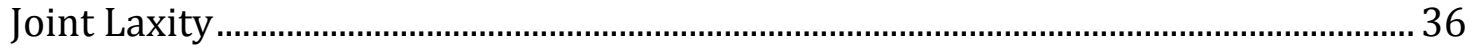

Specific Aim 1: Changes in anthropometry and alignment.......................................... 36

Specific Aim 2: Relationship between anthropometry and alignment changes and

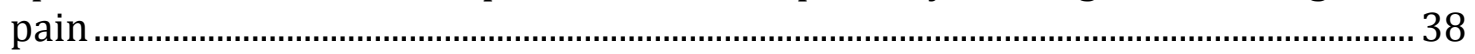

Differences in pain between groups .......................................................................... 38

Correlation between pain and anthropometry/alignment...................................... 40

Correlation between changes in anthropometry/alignment and pain ................. 42

Correlation between left right asymmetry and pain .............................................. 43

Specific Aim 3: Weighted vs. unweighted conditions ................................................... 43

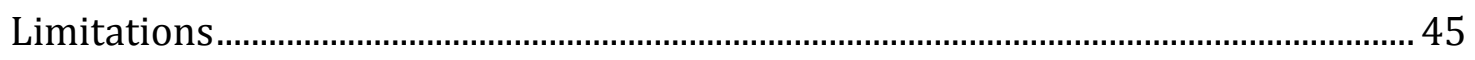

Future research.................................................................................................... 46

Conclusions........................................................................................................ 47

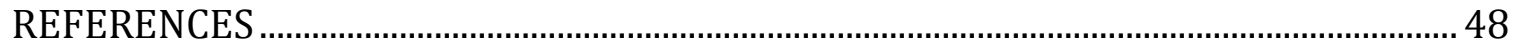

APPENDIX A: Foot Alignment in Pregnancy Telephone Screening Script and Screening Questionnaire................................................................................................. 56

APPENDIX B: Consent and Information Form ................................................................. 58

APPENDIX C: Pregnancy and Foot Study: Lower Extremity Pain Visual Analogue Scale .66 


\section{CHAPTER 1: INTRODUCTION}

Pregnant women often experience lower extremity pain and back pain. The incidence of this pain in pregnancy is at least $50 \%(50-52,64)$. An increase in the prevalence of pain during pregnancy is not surprising, considering that during the gestational period, women experience many hormonal, anthropomorphic and physiological changes as the fetus develops and the body prepares for delivery. Some of these changes include weight gain $(5,12,38)$, an anterior shift in the center of mass (13), alterations in spinal alignment (42), a decrease in abdominal muscle strength (22), and an increase in joint laxity (5).

The increase in joint laxity may be of particular importance when considering the problem of joint pain. Increased joint mobility is thought to be related to the pregnancy hormone Relaxin (1). It is believed that the function of Relaxin is to target the pelvic ligaments, allowing for expansion of the pelvic cavity to create a better 'cradle' in which to carry the fetus (65).

However, Relaxin also affects other ligaments in the body (1). Many women anecdotally report an increase in the size of their feet and a tendency to be more flatfooted during and after pregnancy. These phenomena have not been widely studied, although several authors have reported increased foot width (54) and area of the foot in contact with the ground (48) during pregnancy. Also, increased load-bearing is related to an increase in contact area, foot length, foot width and rearfoot width, along with decreased arch height (6). However, the differential contributions of Relaxin and the increased body weight associated with pregnancy on foot anthropometry have not been explored. 
Many women report lower extremity pain during pregnancy. For example, 29\% of pregnant women report posterior pelvic pain, which includes both sacroiliac joint pain and sciatic nerve irritation (51). Fifty percent of pregnant women report lumbar spinal pain $(6,50,51)$. If this pain resolved following parturition, then it would be a short-term functional concern. However, Vullo et al. (64) reported a higher incidence of leg and foot pain in post-partum subjects when compared to nulliparous controls (56\% vs. 37\%, Odds Ratio 2.3). Thus, this pain is of major concern.

Thus far, the effect of pregnancy on foot shape and pelvic alignment has not been thoroughly studied. More importantly, the link between foot and pelvic malalignment and incidence of foot, posterior pelvic, and lumbar back pain during and following pregnancy has not been investigated. Once this relationship is tested, if a correlation is indeed established, efforts could be made in the prevention of pregnancy-related malalignment, thereby reducing lower extremity and lumbar spinal pain and dysfunction.

\section{Specific Aims}

Specific Aim 1: To quantify the alterations in foot and pelvic alignment during a first pregnancy and compare to a control group of nulliparous women. Specifically, we examined the extent to which foot length, width, arch index, arch height index, arch rigidity index, arch drop, subtalar joint angle, and pelvic obliquity change over the course of a first pregnancy and determined if they diverge from a nulliparous control group.

Hypothesis 1: We hypothesized that foot length, foot width, arch index, arch drop, subtalar joint angle, and pelvic obliquity would increase and that arch height index and arch rigidity index would decrease such that by the third trimester, they would 
be significantly different from the same measures of a nulliparous control group.

Specific Aim 2: To examine the relationship between self-reported measures of foot, posterior pelvic, and lumbar spine pain and biomechanical measures of pelvic and

\section{foot alignment in a group of primigravid women and an age-matched nulliparous} control group.

Hypothesis 2: We hypothesized that biomechanical malalignment in the pelvis and in the foot will be related to the occurrence and severity of foot, posterior pelvic, and lumbar spine pain in both the pregnant women and the control group, and that the pregnant women would experience changes in alignment that are related to increased pain over the course of a first pregnancy.

\section{Specific Aim 3: To examine the effect of added weight on the foot parameters in pregnant women and controls.}

Hypothesis 3: We hypothesized that the pregnancy (i.e. the hormonal effects of Relaxin) would have a larger effect on the foot parameters than would adding the expected amount of weight to be gained during pregnancy to the control group and to the pregnant women in their first and second trimesters.

\section{Background And Significance}

During pregnancy, the hormone Relaxin loosens the pelvic ligaments (1). However, other body ligaments are also affected by Relaxin, including those of the lower extremity and foot $(1,54)$. It is as yet unclear whether the changes in ligamentous laxity affect foot and lower extremity alignment in pregnant women, however anecdotal reports suggest that this may be the case. There has been some support of these reports from Ponnapula 
and Bobert (54), who found increased foot width following pregnancy. Also, several researchers have reported increased foot contact area and maximal plantar pressures during pregnancy $(20,48)$. However, the effect of pregnancy on other foot and pelvis alignment measures, such as foot length, arch height, rearfoot angle, and pelvic obliquity has not been investigated.

In addition to these reports of changes in foot structure, it has been found $30 \%$ of pregnant women report posterior pelvic pain (51), and half of all pregnant women complain of back pain (50). Fifty-six percent of post-partum women report long-term lower extremity pain following pregnancy, while only $37 \%$ of never-pregnant women experience the same type of pain (64).

Previous research has shown a link between pes planus and risk of lower extremity overuse injury (29). However, the association between alterations in foot and lower extremity alignment and foot, posterior pelvic, and lumbar back pain during pregnancy has not been explored.

The proposed study is important because we will quantify alterations in foot and pelvic alignment that occur during pregnancy and the relationship between self-reported foot, posterior pelvic and lumbar pain and foot and pelvic malalignment. This may be a first step towards developing preventative treatments, such as supportive footwear or foot strengthening regimens, which could alleviate and reduce incidence of the pain experienced by pregnant women.

\section{Assumptions}

In the proposed study, assumptions will have to be made in regard to the responses to the pain questionnaires. It will have to be assumed that the participants will 
be honest and accurate in describing and quantifying the pain they are experiencing. Also, it is assumed that any changes in pain occurring during pregnancy are a result of the pregnancy, and not some other lifestyle factor. Finally, it is assumed that biomechanical measurements reflect a change in alignment. It will not be possible to determine if any malalignments existed prior to pregnancy.

\section{Limitations}

Limitations in this study include several lifestyle factors that cannot be controlled outside of the laboratory setting. Many women attempt to remain active during pregnancy, while others tend to become more sedentary during the gestation period (16). Differences in activity may play a role in muscles and joint pain. Also, pre-pregnancy history of activity, fitness and injury could play a role in musculoskeletal factors contributing to joint pain. Finally, by limiting the study to first-time, uncomplicated pregnancies, these results will not apply to multiparous women or those with complicated pregnancies.

\section{Delimitations}

Primigravid women undergoing uncomplicated pregnancies will be selected for this study. Multigravid women will be excluded to control for any persisting musculoskeletal alignment changes that may have resulted from previous pregnancies. Nulligravid controls will be selected for the same reason. Complicated pregnancies will be excluded, as examination of musculoskeletal alignment is desired over the full 
pregnancy term to quantify the full effects of pregnancy on alignment and pain.

Participants will be recruited as early as possible into their pregnancy, ideally within the first trimester, in order to measure the most complete possible range of changes experienced over the course of gestation.

\section{Definitions}

Arch Index (AI) - A ratio between the area of the midfoot divided by the total foot contact area, excluding the toes.

Arch Height Index (AHI) - The ratio between the foot height and the truncated foot length, from the back of the heel to the head of the first metatarsal.

Arch Rigidity Index (ARI) - The ratio between the sitting arch height index and the standing arch height index.

Arch drop (AD) - The sitting arch height index minus the standing arch height index.

Nulliparous - Having never given birth to offspring.

Parturition - Giving birth to offspring.

Pelvic obliquity (PO) - Deviation of the pelvis from the horizontal in the frontal plane.

Pes cavus - High arch.

Pes planus - Flat foot.

Primigravid - Pregnant for the first time.

Rearfoot angle (RA) -Angle between the leg and the heel while standing. 


\section{CHAPTER 2: REVIEW OF THE LITERATURE}

\section{Pain in Pregnancy}

Joint pain, especially in the lower extremity, is a common complaint of pregnant women. Leg and foot pain are more common in pregnant than non-pregnant women (56\% vs. 23\%) (64). Similarly, hip pain is experienced by $38 \%$ of pregnant women, compared with just $23 \%$ of non-pregnant controls (64). Posterior pelvic pain, including sacroiliac and sciatic nerve dysfunction, is found in $29 \%$ of pregnancies (22). Further, half of all pregnant women have back pain, including high-back, lumbar, and sacroiliac pain (50-52). Of these three types of back pain, sacroiliac pain is most prevalent, followed by lumbar and high-back pain (50). The majority of pain has been found to begin in the second and third trimesters (64).

The consequences of joint pain during pregnancy are not limited to discomfort. Severe functional impairment has been found, including use of crutches and waking during the night due to pain (56). Of further concern is that the pain experienced during pregnancy is not limited to the 40-week gestation period. Vullo et al. (64) report that $31 \%$ of women suffer from long-term pain following pregnancy. Thus, dysfunction and disability may continue to affect quality of life beyond the 9-month gestation. Lastly, incidence of pain increases with number of pregnancies (50), suggesting that changes may not abate following pregnancy, and that they may in fact progress with multiple pregnancies. This could mean that a woman with multiple children will spend years of her adult life in pain. 


\section{Bodily Changes During Pregnancy}

During pregnancy, the female body undergoes hormonal, physiological and anthropomorphic changes. There has been much speculation as to which of these types of changes might contribute to back pain. The weight gain associated with pregnancy seems a likely cause, however it has been found to be unrelated to occurrence of back pain $(50,52,64)$.

A more likely factor in occurrence of pain seems to be increased levels of certain hormones experienced during pregnancy. During the gestation period, women produce more sex hormones, such as estrogens and progesterone, as well as glucocorticoids, such as cortisol (55). Relaxin is also associated with pregnancy. It is a peptide hormone of the Insulin-like Growth Factor family. There is as much as a ten-fold increase in Relaxin during pregnancy (5), however there is great individual variability in this response (24). Longitudinal analysis over the course of pregnancy shows that levels rise until the twelfth gestational week, then decline until the $17^{\text {th }}$ week, thereafter remaining stable at $50 \%$ of the peak value (33). Following pregnancy, Relaxin levels return to pre-pregnancy values three months after delivery (33).

\section{Relaxin and joint laxity}

There are several proposed roles for Relaxin during pregnancy, including endometrial maintenance (24), vasodilation (9) and pelvic joint laxity (1). Relaxin affects connective tissue by stimulating turnover of collagen protein (45). This effect of Relaxin, in tandem with other pregnancy hormones, may lead to the significant increases in joint laxity experienced during late pregnancy (5). However, this increase in laxity is not 
limited to the pelvic ligaments. Increase in range of motion is found in several peripheral joints, including the knee, metacarpophalangeal and metatarsophalangeal joints $(4,5,58)$.

Like Relaxin levels, degree of laxity varies among women. Higher levels of Relaxin are associated with greater increase in joint laxity during pregnancy (35). Results from Calnugeri et al. (5) suggest that this effect may be long term, as women pregnant for the second time show greater laxity than primigravid women. There are no further increases in subsequent pregnancies.

In addition to increased joint laxity, Relaxin levels during early pregnancy are positively correlated with pelvic pain later in pregnancy (33-35), although the mechanism is unknown.

\section{Joint alignment and posture}

In addition to changes in joint laxity, it is commonly thought that pregnant women experience changes in foot shape and structure. However, much of this belief stems from anecdote. So far, there is little scientific evidence to support these claims. The area of the foot in contact with the floor, as measured by area of the foot in contact with a force plate during static measurements, increases (48), indicating a possible drop in the longitudinal arch of the foot. Increased area of the footprint points to increased pronation of the foot, as shown by Block et al. (4), who found increased pronation of the mid- and rearfoot, putting the foot in a more valgus angle. However, footprint-based measurements may be confounded in pregnant women by swelling of feet. Thus, further research is required to determine the effect of pregnancy on foot shape and structure.

In non-pregnant humans, weight-bearing influences foot shape and structure. Increased weight-bearing, from sitting to standing, causes an increase in foot length, foot 
width and rearfoot width, as well as decreased average height, arch height and arch angle of the foot (63). This could be of relevance to the current topic, as pregnant women normally experience a weight gain of about $12.6 \mathrm{~kg}(52)$. While pregnant women experience several other changes that may also influence foot structure, these results suggest that the weight gain alone of pregnancy may put women at risk of lower arch height.

Minor alignment changes are also found at the level of the hip and spine during pregnancy, compensating for significant anterior weight gain. However, conflicting results as to the nature of these changes are found. Gilleard et al. (21) and Okanishi et al. (49) report average increases in lumbar kyphosis, or lumbar flattening, while Franklin et al. (18) found an increase in lumbar lordosis and anterior pelvic tilt, as well as a posterior displacement of the head position during pregnancy. All authors concur that there is significant inter-individual variability between subjects, likely contributing to the difference in results between studies.

It has been suggested that postural changes adopted to improve stability might stress lumbar and pelvic muscles, contributing to pain during pregnancy. Exercises aimed at attenuating lordosis are a common intervention for pregnancy-related back pain. However, the effectiveness of such treatment is not ubiquitously supported by the literature. Kashanian et al. (28) report a decrease in pain and lordosis with an exercise program in pregnant subjects. However, Franklin et al. (18) found no relationship between lordosis and back pain. Thus, other measures of malalignment may contribute to back pain in pregnancy. All available literature has examined sagittal plane measures of posture. No data have been found on measures of frontal plane alignment, such as pelvic 
obliquity. Calcaneal eversion, both bilateral and unilateral, does impact pelvic alignment as measured by pelvic obliquity (53). Calcaneal eversion is a component of pronation, which increases in some women during pregnancy (4). Thus, pregnant women who experience increased pronation of the foot may be at risk for pelvic malalignment.

\section{Relationship between alignment and back pain}

Low back pain may often be attributable to malalignments in the lower extremity. Military personnel with moderate to severe flat-feet have a higher incidence of low back pain (31). Pelvic alignment is also a risk factor for low back pain. Leg length discrepancy resulting in pelvic obliquity results in increased occurrence of back pain (57). Despite these findings in the general population, the relationship between alignment and back pain during pregnancy has not been explored.

\section{Gait}

Anthropomorphic changes in pregnancy influence not only static posture, but dynamic gait characteristics as well. Walking velocity generally decreases $(17,38,67)$, and kinematic and kinetic changes, such as increased force production at the hip and ankle (17), and increased back extension (37) are found.

A so-called "waddling" gait, referring to a wide stance gait with the feet spread farther apart, is often associated with that of a pregnant woman. However, the veracity of this association is disputed in the literature. Bird et al. (3), reported findings of wider base of gait during walking. In contrast, Foti et al. (17) reveal a lack of kinematic changes in walking associated with pregnancy. Both groups did note great variability 
between individuals in kinematic changes. Increased pelvic and spinal rotation is demonstrated by those women who experience pelvic pain while pregnant (67).

Therefore, altered gait as a result of pregnancy may contribute to pelvic and back pain in two ways. First, through greater amplitude of trunk rotation (67), and secondly through increased demand on hip and ankle muscles leading to fatigue and musculoskeletal pain (17).

\section{Activity level}

As a chronic injury, it can be expected that activity stressing the lower extremity might affect incidence and severity of back pain. For example, certain vocational characteristics have been found to be risk factors for back pain during pregnancy, including perceived physical heaviness of work, frequency of twisting and forward bending, constrained or sitting work posture, and inability to take rests breaks during the work day (50). In a study comparing Beninese and Canadian women, it was found that the pregnant Beninese women, who worked 18 hours more each week than the Canadian women, had a greater prevalence of back pain (83\% vs 58\%) (7). Further, 33\% of Beninese women reported severe disability, vs just $14 \%$ of Canadian women (7).

In terms of home activities, no difference was found in number of stairs in the home or frequency of stair climbing between pregnant women with back pain and those without (64). Similarly exercise participation was found to have no effect on occurrence of back pain $(12,60,64)$. 


\section{Targeted exercise treatment}

Although general exercise does not influence back pain, targeted exercise aimed at strengthening the back and pelvis with the goal of reducing back pain is a common intervention. Mixed results have been found as the to the efficacy of pelvic and spinal stabilizing exercises. This type of program was found to reduce back pain intensity from 30 to 18.5 , on a scale from $0-60$, and improve functional ability, in a randomizedcontrolled trial on a population of pregnant South-African women (30). This finding is supported by another randomized-controlled trial comparing the effects of stabilizing exercises vs. regular physical therapy on back pain during pregnancy (62). However, in a randomized-controlled trial conducted in Sweden, no difference in pain was found between exercising and control groups (26).

As is found with research into the effects of strengthening exercises on back pain in pregnancy, the role of muscle weakness is also controversial. Dumas et al. (12) show that fatigability of back extensors is not a predictor of back pain during pregnancy. Similarly, abdominal strength, while diminished in pregnant women, is not correlated with back pain (15). In contrast, Gutke et al. (25) related trunk muscle endurance and hip extension strength to incidence of back pain during pregnancy. Therefore, while pelvic and back stability in some instances seem to play a role, they may not be the sole issue that needs to be addressed when treating back pain in pregnant women.

Exercises targeting the pelvic floor muscles may have more success. A randomized-controlled trial found that a program of daily pelvic floor exercises combined with weekly group classes including aerobic work and other exercises reduced 
occurrence of back pain from $56 \%$ to $44 \%$ during pregnancy, and from $37 \%$ to $26 \%$ three months post-partum (43).

To date, research into treatment methods for back pain in pregnancy is limited to stabilization of the back and pelvis. To the author's knowledge, no other treatment methods, successful or otherwise, have been studied in the current literature. 


\section{CHAPTER 3: METHODS}

\section{General Outline}

A repeated measures experimental design was employed for this prospective feasibility study. Fifteen primigravid women aged 18-45 were recruited to participate. Thirteen controls who had never been pregnant also participated. Pregnant and control subjects were matched based on the pregnant subject's self-reported pre-pregnancy body weight. Data of the pregnant group were collected in the middle of the first, second, and third trimesters, as well as post-partum. Data from the control group were collected one time. Each data collection visit lasted approximately forty-five minutes. Subjects were surveyed about their current foot, posterior pelvic, and lumbar spine pain. During each visit, measurements were made on foot structure and pelvic alignment.

\section{Subjects}

Fifteen pregnant women and 13 nulliparous controls between the ages of 18 and 45 years were recruited from the greater Morgantown area (Table 1). One subject gave birth prematurely, before her $3^{\text {rd }}$ trimester measurements were obtained. Her data were excluded from pain correlation analysis. At the time of defense, two subjects had not yet reached the post-partum time point. Case participants were required to have been in their first pregnancy. Controls were matched to pre-pregnancy body weight. Subjects were recruited through several methods. Advertisements for the study were placed in the WVU Health Sciences Center and in WVU Healthcare facilities. Pregnant women were also recruited from the clinical obstetrics practices at WVU Healthcare. Interested women 
were asked to contact the investigators for a screening interview (Appendix A). The interview was administered orally over the telephone. They were asked whether they meet with exclusion criteria, including if they had lost more than $15 \%$ body weight, if they had been pregnant previously, or if they had a history of lower extremity fracture or sprain within the last year.

Table 1. Subject demographics.

\begin{tabular}{|l|l|l|l|l|}
\hline Trimester & Age (yrs) & Height $(\mathbf{c m})$ & Mass $(\mathbf{k g})$ & $\begin{array}{l}\text { Weeks } \\
\text { Pregnant }\end{array}$ \\
\hline Control & $22.0 \pm 1.5$ & $164.0 \pm 4.6$ & $62.0 \pm 7.7$ & 0 \\
\hline Pregnant & $29.0 \pm 3.58^{*}$ & $167.7 \pm 6.4$ & $63.0 \pm 8.8^{* *}$ & \\
\hline $\mathbf{1}^{\text {st }}$ trimester & & & $62.7 \pm 8.8$ & $10.8 \pm 2.2^{*}$ \\
\hline $\mathbf{2}^{\text {nd }}$ trimester & & & $73.1 \pm 11.9$ & $25.0 \pm 2.0^{*}$ \\
\hline $\mathbf{3}^{\text {rd }}$ trimester & & & $79.6 \pm 13.5^{*}$ & $36.1 \pm 1.1^{*}$ \\
\hline Post-partum & & & $68.5 \pm 14.2$ & 0 \\
\hline
\end{tabular}

*statistically significant difference from control group. Pregnant subjects were significantly older than controls, and heavier in their $2^{\text {nd }}$ and $3^{\text {rd }}$ trimesters. **pre-pregnancy

\section{Procedures}

\section{Informed Consent}

Data collection took place at the WVU Healthcare's Physicians Office Center or WVU Healthcare's Cheat Lake Physicians Office Center. Data were also collected at the West Virginia University's Human Performance Lab on the $8^{\text {th }}$ floor of WVU's Health Sciences Center. All equipment was portable, so testing could be conducted at the most convenient location for each subject. At her initial visit, the experimental protocol was explained to the subject and written informed consent, approved by WVU's Institutional Review Board for the Protection of Human Subjects was obtained (Appendix B). 
Subjects were asked to wear their own snug fitting clothing.

\section{Pain Assessment}

Subjects were surveyed about current pain in the lower extremity through the use of a visual analogue scale (VAS) questionnaire (Appendix C). This questionnaire was designed based on the previously validated VAS Foot and Ankle (61). A series of six questions were asked about pain and disability at each of the lower back (LB), hip/buttocks (HB), upper leg (UL), knee (K), lower leg (LL) and foot/ankle (FA). For each question, a $10 \mathrm{~cm}$ horizontal line was provided, on which the subject was asked to place a mark to indicate the severity of her symptoms, with the left indicating worst possible pain, and right indicating no pain. The distance from the leftmost point of the line to the mark was measured to the nearest millimeter, to give a score out of 10 . The score for each of the six questions at each location was added together and divided by 6 , to give a total score out of 10 at each location. Ten on this scale indicated no pain, and 0 indicated worst imaginable pain.

\section{Biomechanical Assessment}

First, the subject's weight was measured using a standard bathroom scale (2020W Mechanical Rotating Dial Scale, Taylor Precision Products, Oak Brook, IL). To assess pelvic, lower extremity, and foot alignment, a series of biomechanical measurements were taken at each visit. These measurements were taken bilaterally on the subjects. The left or right side was randomly selected to be assessed first at each subject/visit.

With the subject in a standing position with feet shoulder width apart, foot length (FL) and foot width (FW) were measured using a standard anthropometer (Lafayette 
Instrument Company, Model 01291). FL was measured as the distance from the most anterior aspect of the foot to the most posterior aspect (Intrarater reliability Pearson correlation coefficient: 0.99). FW was measured as the distance between the most medial to the most lateral aspects of the forefoot (Intrarater reliability Pearson correlation coefficient: 0.96). Measurements were recorded in centimeters. Measurements were then taken of the contralateral foot. Leg length was measured with the subject lying in a supine position. The distance in centimeters from the greater trochanter to the apex of the lateral malleolus of each leg was recorded.

Next, to get a measure of hypermobility, subjects were assessed on the Beighton Ligamentous Laxity scale. This test involves a series of six tests for flexibility, including flexion at the hip to touch the floor, hyperextension of the knees, touching the thumbs to the forearm, extension of the small finger beyond $90^{\circ}$ and hyperextension of the elbows. Each task that the subject is capable of completing will be given one point, for a score out of nine possible points. The subject was not forced to stretch beyond their comfort level. The higher the score received, the higher the degree of laxity.

Arch index (AI), an indirect assessment of arch height, was measured according to the methods described by Cavanagh and Rodgers (6) (Intrarater reliability Pearson correlation coefficient: 0.85). Each subject was instructed to stand on a typical analog bathroom scale. She was then asked to place one foot an inkpad (Aetrex Harris Mat) located on the side of the scale so that her feet were $15 \mathrm{~cm}$ apart. The inkpad is designed such that the subject does not come in contact with the ink and no ink gets on

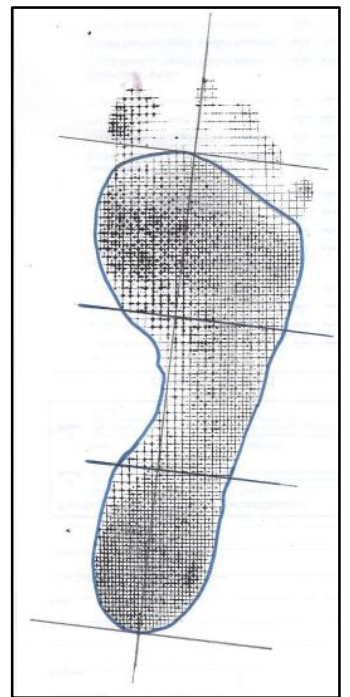

Figure 1 Arch Index footprint. 
the subject's foot. The subject was instructed to transfer her weight so that half of her weight was still on the scale, and half of it was on the inkpad. An inked footprint was obtained in this manner (Figure 1). AI was calculated using the NIH software ImageJ (NIH, Bethesda, MD). Specifically, on the footprint, a line was drawn from the tip of the second toe to the most posterior aspect of the heel. Distance from the anterior portion of the forefoot (not including the toes) to the posterior heel was measured along this line. This distance was divided into thirds and corresponding markers were made along the line on the footprint. The most anterior portion of the footprint is termed the forefoot, and the middle and posterior regions are termed the midfoot and rearfoot, respectively. The areas of the midfoot and total footprint were determined. AI was calculated as the area of midfoot / total area of the footprint (6). Increased AI indicates a lower arch, such that an $\mathrm{AI}<0.21$ is considered pes cavus, an $\mathrm{AI}>0.26$ is considered pes planus, and an $\mathrm{AI}$ between 0.21 and 0.26 is considered normal (6). Measurements were made on both the left and right feet.

Several foot alignment measures were obtained using the Arch Height Index Measurement System (Intrarater reliability Pearson correlation coefficient: 0.95). Using a set of sliding calipers (Figure 2. JAK Tool, New Jersey, New York), elevated on two wooden blocks to leave the medial

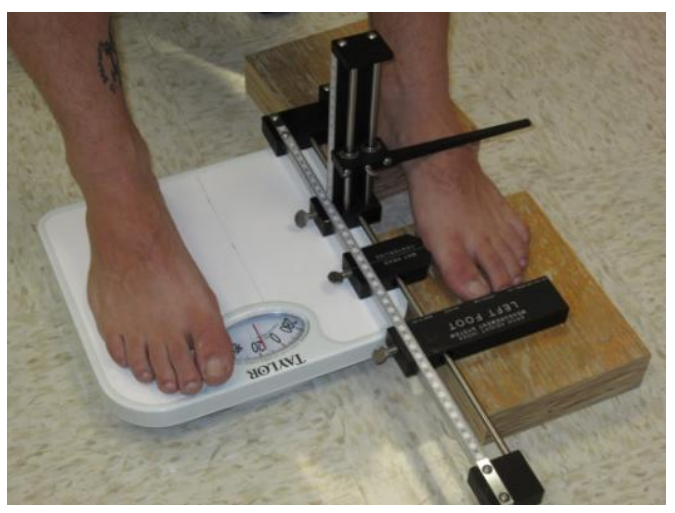

Figure 2 Arch Height Index Measurement System longitudinal arch unsupported, we took three measurements of each foot: foot length (FL), truncated foot length (TFL), which is the 
distance from the most posterior aspect of the heel to the head of the first metatarsal, and foot height $(\mathrm{FH})$, which is the height of the foot at $1 / 2$ total foot length. Measurements were taken seated, using a goniometer to place the ankle in a position such that the line between the first metatarsal head and the lateral ankle formed a $120^{\circ}$ angle with the line from the lateral ankle to the head of the fibula. Then the same measures were taken standing, with weight evenly distributed on both feet. Several calculations were made using these measurements. Seated arch height index $(\mathrm{AHI})=$ seated FH/seated TFL. Standing AHI = standing FH/standing TFL. Higher values of AHI indicate higher arches. Arch rigidity index (ARI) and arch drop (AD) are measures of arch flexibility. ARI = standing AHI/seated AHI. An ARI of 1 indicates a perfectly rigid arch, while values closer to 0 indicate a more flexible arch. $\mathrm{AD}=$ seated $\mathrm{FH} /$ standing $\mathrm{FH}$. A greater AD indicates a more flexible arch.

Rearfoot angle (RA) was also measured by photogrammetry, according to the methods of Clarke (8) (Intrarater reliability Pearson correlation coefficient: 0.90). An anthropometer (Lafayette Instrument Company, Model 01291) was placed on the head of the fibula and the medial point on the leg directly across from the fibular head, and a line bisecting the knee joint line was dropped to locate and mark the midpoint of the subject's legs at the musculotendinous intersection of the gastrocnemius and on the Achilles tendon. While participants knelt on a chair facing the back, the subtalar joint was placed in a neutral position and marks were made on the midpoint of the

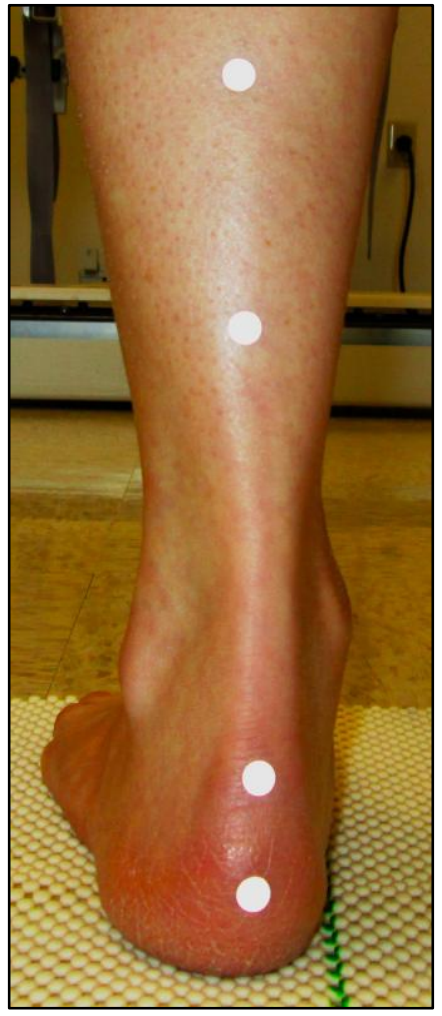

Figure 3. Rearfoot angle . 
calcaneus and Achilles. The subject was asked to stand in a relaxed position with feet 15 cm apart. Reflective markers were placed on marked locations on both legs (Figure 3). A digital camera (Canon EOS Rebel T2i, Tokyo, Japan) was placed on a wooden block at a height of $10 \mathrm{~cm}, 55 \mathrm{~cm}$ directly behind the subject. A photograph was taken of both legs. Using ImageJ software, the rearfoot angle was calculated as the angle between the lines from the midpoint of the knee joint and the gasctrocnemius insertion, and the gastrocnemius insertion and the midpoint of the calcaneus. Increased rearfoot angle indicates increased pronation. Measurements were obtained for both legs.

Finally, pelvic obliquity (PO), or the angle that the pelvis makes with the horizontal in the frontal plane, was measured (Intrarater reliability Pearson correlation coefficient: 0.78). To do this, an experienced investigator palpated the subjects' left and right anterior superior iliac crests of the pelvis. Reflective markers $(1 \mathrm{~cm})$ were placed on these landmarks. The height of these markers from the floor was measured with an aluminum square ruler. The camera was positioned perpendicular to the subject. The

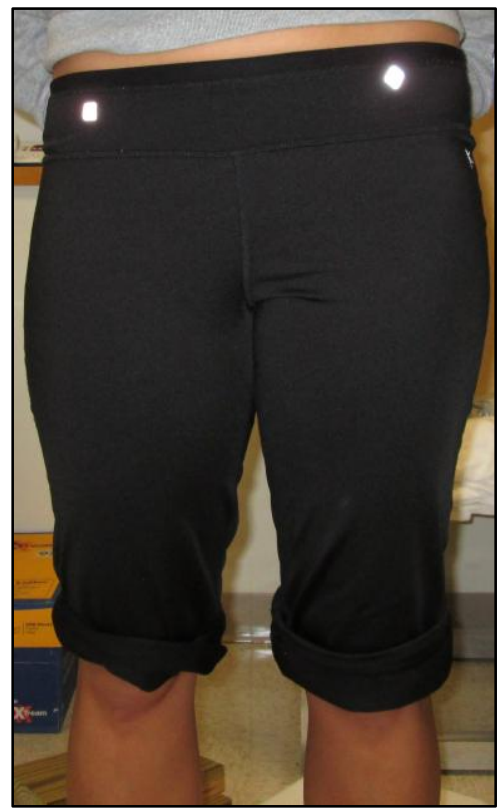

Figure 4. Pelvic obliquity. subject was positioned with her feet $15 \mathrm{~cm}$ apart. A digital photograph was obtained (Figure 4). Using ImageJ software, pelvic obliquity, or the angle between a line connecting the left and right ASIS markers and the horizontal was determined. 


\section{Weighted and Unweighted}

For control subjects, as well as case subjects at early pregnancy visits and postpartum, who did not carry the full weight of pregnancy, participants were measured both unweighted and with a backpack worn on the front, weighted to add the remainder of weight expected to be gained during pregnancy (except for pelvic obliquity measurements, where the backpack would cover the markers). Previous data found the average weight gain by the third trimester to be $12.6 \mathrm{~kg}(38)$. Therefore, we weighted the back-pack so the total weight of the patient plus the vest equaled pre-pregnancy weight plus $12.6 \mathrm{~kg}$. This allowed for examination of the effect of added weight on foot shape, independent of hormonal influences.

Control subjects were weighted with the amount of weight gained by the pregnant subject with whom they are matched. Therefore, control subjects were recruited for each pregnant subject after the pregnant subject had their $3^{\text {rd }}$ trimester study visit. Similarly,

for her post-partum weighted measurements, each subject was weighted to match her $3^{\text {rd }}$ trimester weight.

\section{Statistical Analysis}

The statistical analysis was performed using the IBM SPSS Statistics software (Armonk, New York). Demographics (e.g., age, gender, height, weight) of the study population were determined. Descriptive statistics, including measures of central tendency (means) and dispersion (standard deviations) were computed for continuous data.

Specific Aim 1 was to determine if pregnancy is related to alterations in foot and pelvic alignment. Specific Aim 3 was to determine the effect of added weight on 
measures of alignment. There were a number of dependent variables: FL, FW, AI, AHI, ARI, AD, RA and PO. Data for left and right feet were pooled for analysis. The independent variables were trimester (control, $1^{\text {st }}$ trimester, $2^{\text {nd }}$ trimester, $3^{\text {rd }}$ trimester, and post-partum) and weight condition (unweighted (i.e. natural) or weighted (wearing a pack with the weight expected to be gained by the full-term of pregnancy)). To determine difference between groups and conditions, three MANOVA were performed on the dependent variables $(\alpha=0.1)$. The first with trimester as the independent factor, the and one with weight condition as the factor, and the third compared trimesters in the weighted condition (ie. Weighted controls vs. weighted $1^{\text {st }}$ trimester vs. weighted $2^{\text {nd }}$ trimester, vs $3^{\text {rd }}$ trimester vs. weighted post-partum). If differences were found between trimesters for a particular dependent variable, a Tukey post-hoc analysis was performed on that variable. Due to the prospective nature of this study, $\alpha=0.1$. Where $0.05<p<0.1$, a power analysis was performed to determine the number of subjects that would be required to achieve significance at $\alpha=0.05$.

Specific Aim 2 was to assess if malalignment is associated with pain. Due to the ceiling effect of the pain scale, these data were not normally distributed. Therefore, a Kruskal-Wallis Test was used to determine if pain at the low back, hip/buttocks, upper leg, knee, lower leg and foot/ankle were different between trimesters $(\alpha=0.1)$. SpearmanRho correlation coefficients between lower extremity measurements and pain were calculated between each lower extremity measure and each location of pain across all subjects $(\alpha=0.1)$. Also, for pregnant subjects, changes in lower extremity anthropometric and alignment measures in pregnant subjects were quantified by subtracting $2^{\text {nd }}$ trimester measurements from $3^{\text {rd }}$ trimester measurements, and change in pain was calculated by 
subtracting $2^{\text {nd }}$ trimester pain from $3^{\text {rd }}$ trimester pain. Pearson correlation coefficients between lower extremity alignment changes and changes in pain were calculated $(\alpha=0.1)$.

Finally, to determine the influence of left/right asymmetry on pain, Spearman-Rho correlations between differences in measures between the left and right sides in each subject and pain were calculated $(\alpha=0.1)$. For all correlations, simple percentile bootstrapping with 1000 samples was performed to determine the $95 \%$ confidence interval $(95 \% \mathrm{CI})$ of the r-value. 


\section{CHAPTER 4: RESULTS}

\section{Joint laxity}

Beighton's test results differ between groups $(\mathrm{p}=0.03)$. Scores were highest in controls (mean 1.7, range $0-5$ ) and lowest in post-partum (mean 0.3 , range $0-2$ ) (Table 2).

Table 2. Beigthon's scores.

\begin{tabular}{|l|l|l|}
\hline \multirow{2}{*}{ Group } & \multicolumn{2}{|l|}{ Beighton's score } \\
\cline { 2 - 3 } & Mean & Range \\
\hline Control & 1.7 & $(0-5)$ \\
\hline $\mathbf{1}^{\text {st }}$ trimester & 1 & $(0-4)$ \\
\hline $\mathbf{2}^{\text {nd }}$ trimester & 1.3 & $(0-5)$ \\
\hline $3^{\text {rd }}$ trimester & 0.6 & $(0-4)$ \\
\hline Post-partum & 0.3 & $(0-2)$ \\
\hline
\end{tabular}

\section{Specific Aim 1: Changes in anthropometry and alignment}

Specific Aim 1 was to assess changes in foot and lower extremity anthropometric and alignment measures over the course of a first pregnancy. These measures included FL, FW, AI, AHI, ARI, AD, RA and PO. Pregnant women experienced some changes in foot anthropometry. FL (Figure 5. $\mathrm{p}=0.04$ ) and AI (Figure 6, $\mathrm{p}=0.07$, power analysis $\mathrm{n}=27$ ) increased significantly, such that by the $3^{\text {rd }}$ trimester pregnant subjects were significantly different from controls. FL remained significantly increased post-partum. PO was different between groups ( $\mathrm{p}=0.098$, power analysis $\mathrm{n}=61$ ), however post-hoc analysis was unable to tell which groups were significantly different (Figure 7). No significant changes were found in any other measures of anthropometry or alignment (Table 3). 


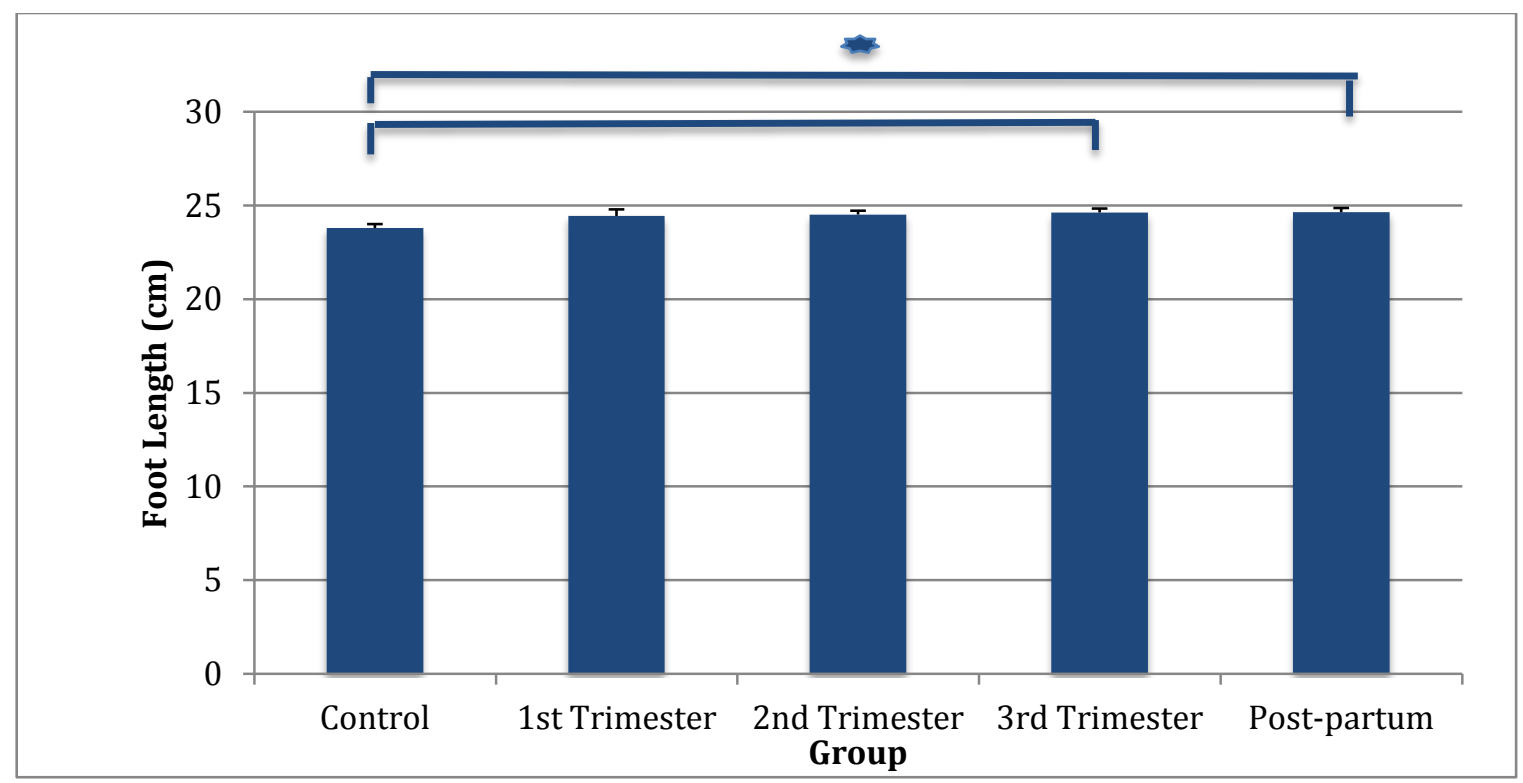

Figure 5. Foot length in control, $1^{\text {st }}$ trimester, $2^{\text {nd }}$ trimester, $3^{\text {rd }}$ trimester and postpartum subjects

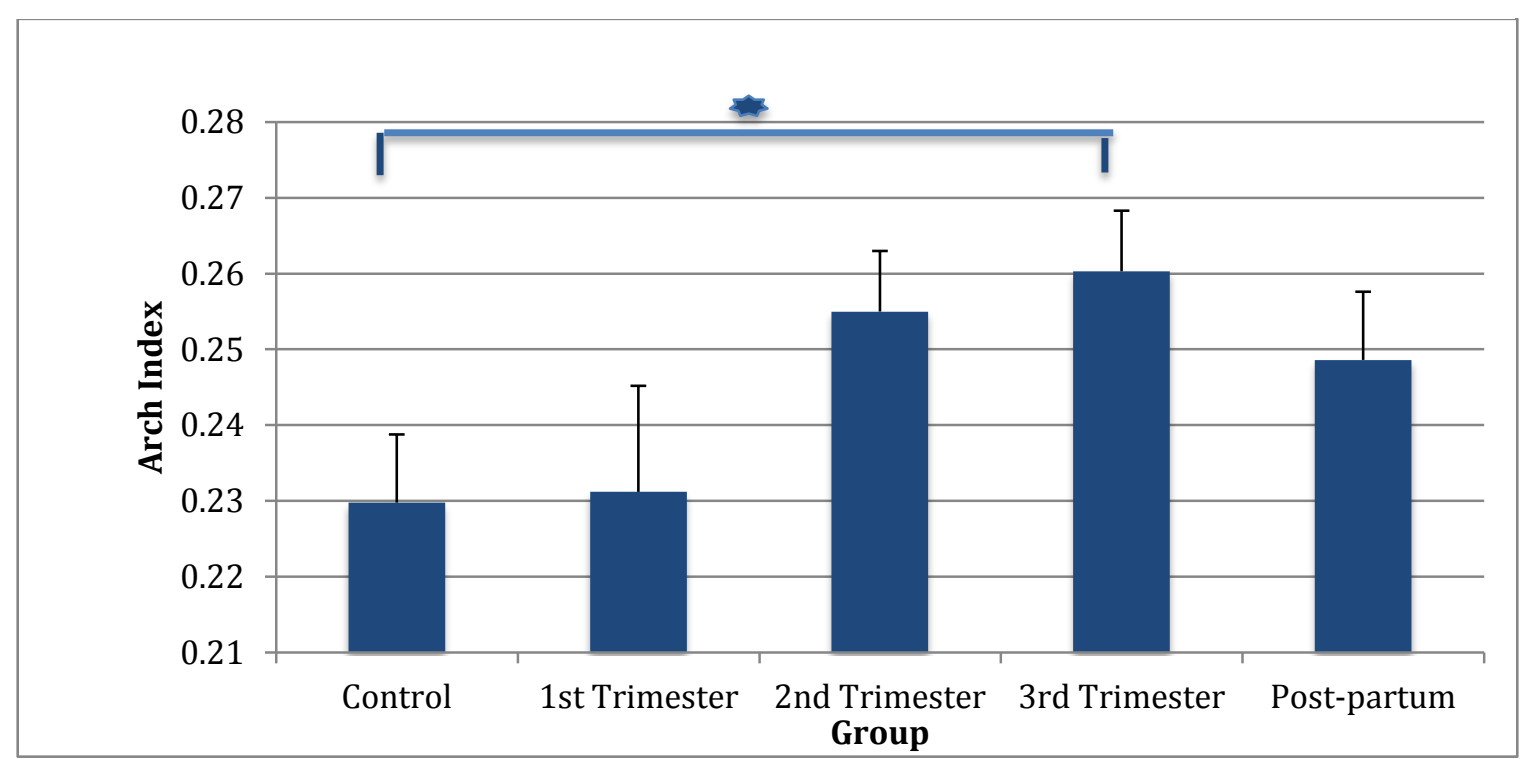

Figure 6. Arch index in control, $1^{\text {st }}$ trimester, $2^{\text {nd }}$ trimester, $3^{\text {rd }}$ trimester and postpartum subjects 


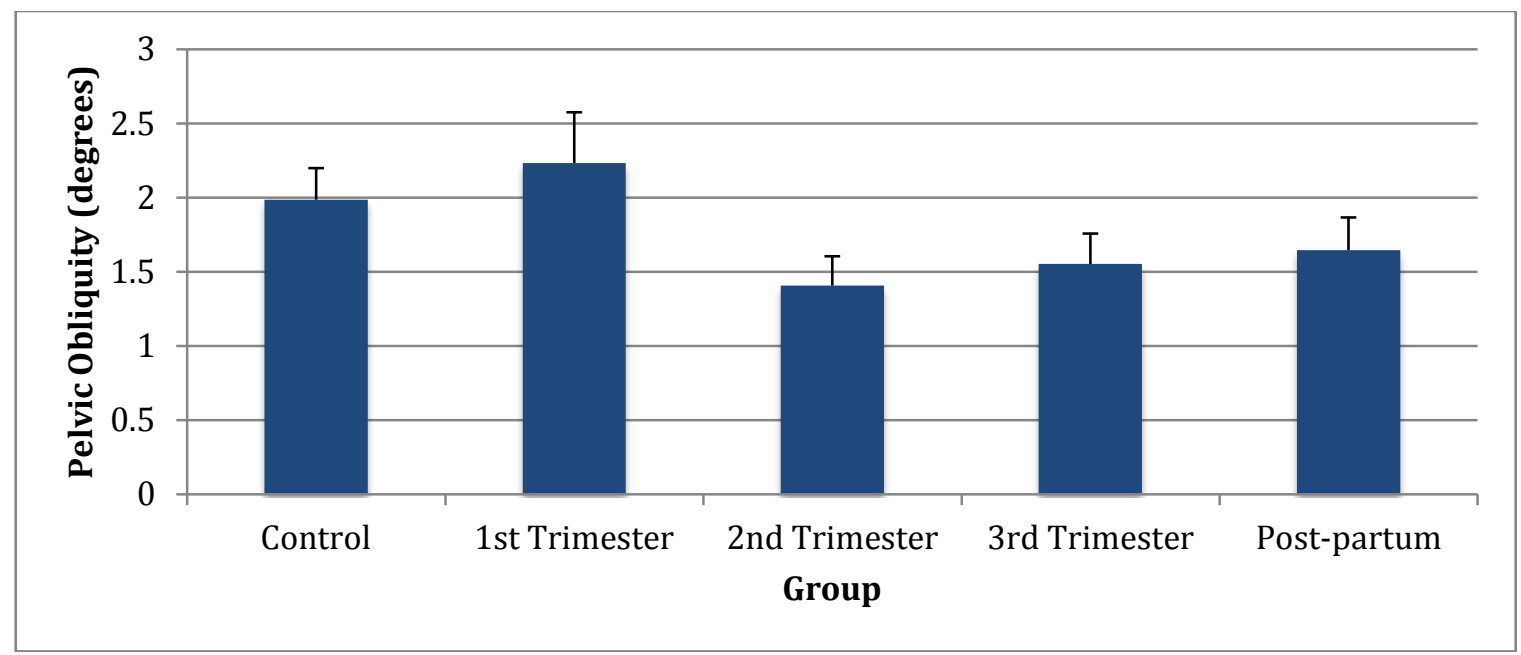

Figure 7. Pelvic obliquity in control, $1^{\text {st }}$ trimester, $2^{\text {nd }}$ trimester and $3^{\text {rd }}$ trimester subjects.

Table 3. Non-significant changes in lower extremity measures.

\begin{tabular}{|l|l|l|l|l|l|l|}
\hline & Control & $\begin{array}{l}\mathbf{1}^{\text {st }} \\
\text { trimester }\end{array}$ & $\begin{array}{l}\mathbf{2}^{\text {nd }} \\
\text { trimester }\end{array}$ & $\begin{array}{l}\mathbf{3}^{\text {rd }} \\
\text { trimester }\end{array}$ & $\begin{array}{l}\text { Post- } \\
\text { partum }\end{array}$ & $\mathbf{p}$ \\
\hline FW (cm) & $8.9 \pm 0.7$ & $9.2 \pm 0.7$ & $9.3 \pm 0.7$ & $9.2 \pm 0.8$ & $9.3 \pm 0.7$ & 0.213 \\
\hline $\begin{array}{l}\text { Standing } \\
\text { AHI }\end{array}$ & $0.33 \pm 0.02$ & $0.31 \pm 0.02$ & $0.32 \pm 0.03$ & $0.33 \pm 0.03$ & $0.32 \pm 0.03$ & 0.159 \\
\hline ARI & $0.93 \pm 0.03$ & $0.92 \pm 0.03$ & $0.92 \pm 0.02$ & $0.91 \pm 0.03$ & $0.92 \pm 0.03$ & 0.134 \\
\hline AD (cm) & $0.36 \pm 0.15$ & $0.37 \pm 0.12$ & $0.39 \pm 0.13$ & $0.46 \pm 0.15$ & $0.41 \pm 0.16$ & 0.102 \\
\hline RA $\left(^{\circ}\right)$ & $183.1 \pm 2.9$ & $183.3 \pm 2.9$ & $183.0 \pm 3.9$ & $183.2 \pm 3.9$ & $182.9 \pm 4.6$ & 0.996 \\
\hline
\end{tabular}

\section{Specific Aim 2: Relationship between anthropometry and alignment changes and pain}

A second purpose of this study was to examine the level of pain in pregnancy, the relationship between pain and absolute athropometric and alignment measures (FL, FW, AI, AHI, ARI, AD, RA, PO) and the relationship between changes in anthropometry/alignment and changes in pain. 


\section{Differences in pain between groups}

To determine if there were differences in severity of pain between controls and pregnant subjects in their $1^{\text {st }}$ trimester, $2^{\text {nd }}$ trimester, $3^{\text {rd }}$ trimester and post-partum, a Kruskal-Wallis Test was performed on the distribution of pain at each location. A score out of 10 at each location was obtained via VAS scale. On this scale, 10 indicates no pain, and 0 indicates worst pain imaginable. Pain levels for each group at each location are shown in Figure 8. Significant differences in pain between groups were found at the low back ( $\mathrm{p}=0.000)$, hip/buttocks $(\mathrm{p}=0.000)$, upper leg $(\mathrm{p}=0.000)$, knee $(\mathrm{p}=0.000)$ and lower leg $(\mathrm{p}=0.001)$. Difference in pain between groups at the foot/ankle was not significant $(\mathrm{p}=0.114)$.

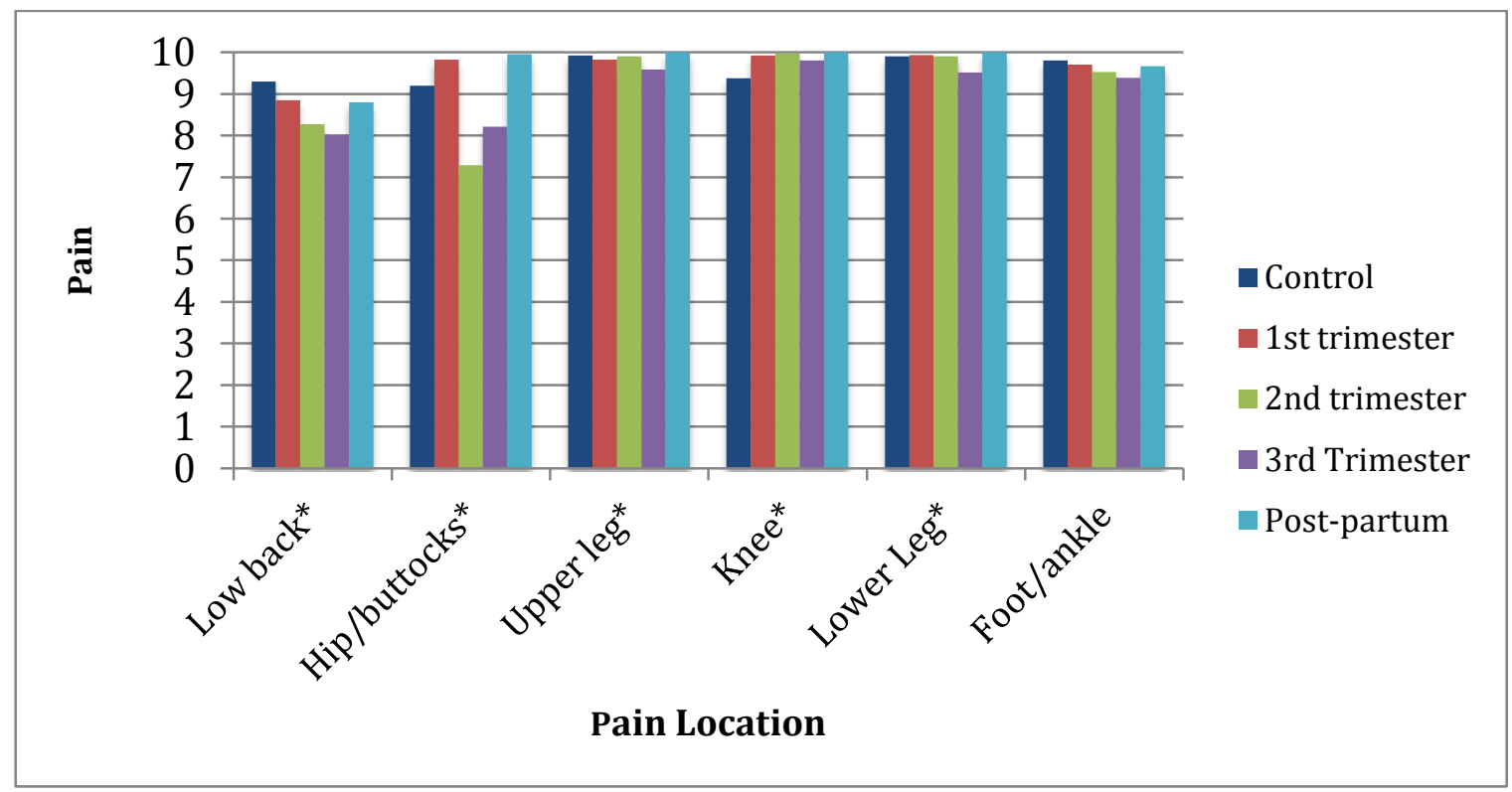

Figure 8. Pain ratings based on scores from VAS scale (median values shown). *p $<0.05$ 


\section{Correlation between pain and anthropometry/alignment}

In terms of the relationship between anthropometry and alignment and pain, certain lower extremity measures were related to pain, across all subjects (Table 4). AI was positively correlated to pain at the upper leg $(\mathrm{p}=0.06, \mathrm{r}=0.175,95 \% \mathrm{CI}:-0.198$ to $0.166)$, knee $(\mathrm{p}=0.002, \mathrm{r}=0.287,95 \% \mathrm{CI}: 0.059$ to 0.477$)$ and lower leg $(\mathrm{p}=0.03, \mathrm{r}=0.205$, 95\% CI: 0.023-0.366). ARI was positively correlated to changes in pain at the low back $(p=0.03, r=0.203,95 \%$ CI: $0.034-0.366)$ and foot $/$ ankle $(p=0.005, r=0.255,95 \%$ CI:

$0.062-0.420)$. AD was negatively correlated to pain at the low back $(\mathrm{p}=0.01, \mathrm{r}=-0.231$, 95\% CI: -0.386 to -0.055$)$, and foot/ankle ( $\mathrm{p}=0.004, \mathrm{r}=-0.266,95 \% \mathrm{CI}:-0.437$ to -0.084$)$.

RA was positively correlated with pain at the foot/ankle ( $p=0.07, r=0.169,95 \%$ CI: 0.022 to 0.345$)$. PO was positively correlated with pain at the foot/ankle $(\mathrm{p}=0.07$, $\mathrm{r}=0.169,95 \%$ CI: -0.017 to .0346$)$.

Table 4. Spearman-Rho correlation coefficients between lower extremity measurements and pain.

\begin{tabular}{|l|l|l|l|l|l|l|}
\hline & LB & HB & UL & K & LL & FA \\
\hline AI & -0.137 & -0.010 & $0.175^{*}$ & $0.287^{* *}$ & $0.205^{* *}$ & -0.064 \\
\hline $\begin{array}{l}\text { Standing } \\
\text { AHI }\end{array}$ & 0.123 & -0.129 & -0.017 & -0.036 & -0.114 & -0.136 \\
\hline ARI & $0.203^{* *}$ & -0.151 & 0.033 & -0.086 & -0.037 & $0.255^{* *}$ \\
\hline AD & $-0.231^{* *}$ & 0.049 & -0.040 & 0.058 & 0.006 & $-0.266^{* *}$ \\
\hline RA & 0.023 & 0.031 & 0.102 & 0.042 & 0.108 & $0.169^{*}$ \\
\hline PO & 0.017 & 0.078 & -0.098 & -0.010 & 0.086 & $0.169^{*}$ \\
\hline
\end{tabular}

$* 0.05<p \leq 0.1 * * p \leq 0.05$ 


\section{Correlation between changes in anthropometry/alignment and pain}

Changes in certain alignment measures in $3^{\text {rd }}$ trimester participants were significantly correlated to changes in pain. Change in FW was negatively correlated to change in pain at the low back (Figure 9, $\mathrm{p}=0.09, \mathrm{r}=-0.330,95 \%$ CI: -0.698 to 0.311 ), and at the knee (Figure 10, $\mathrm{p}=0.04, \mathrm{r}=-0.384,95 \% \mathrm{CI}$ : 0.068 to -0.690 ). Change in standing AHI was negatively correlated to change in pain at the low back (Figure 11, p=0.02, r=$0.447,95 \%$ CI: -0.754 to 0.132 ) . Change in PO was positively correlated to change in pain at the low back (Figure 12, $\mathrm{p}=0.03, \mathrm{r}=0.424,95 \%$ CI: 0.052 to 0.710 ) and hip/buttocks (Figure 13, p=0.05, r=0.377, 95\% CI: 0.027 to 0.699). Changes in AI, ARI, $\mathrm{AD}$ and RA were not related to any changes in pain. Correlations between changes in lower extremity measurements and changes in pain are shown in Table 5.

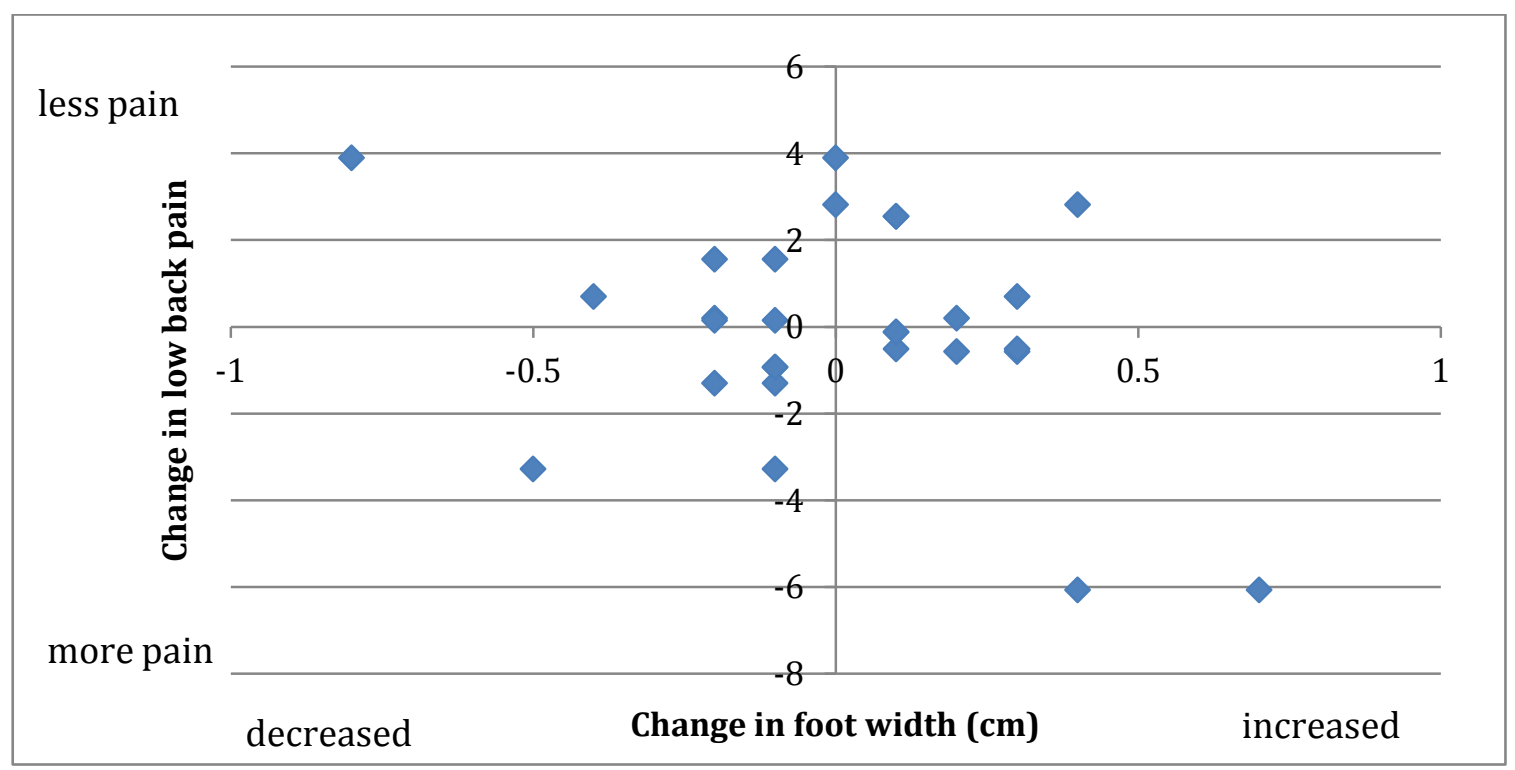

Figure 9. Change in foot width vs. change in low back pain. $r=-0.330$ 


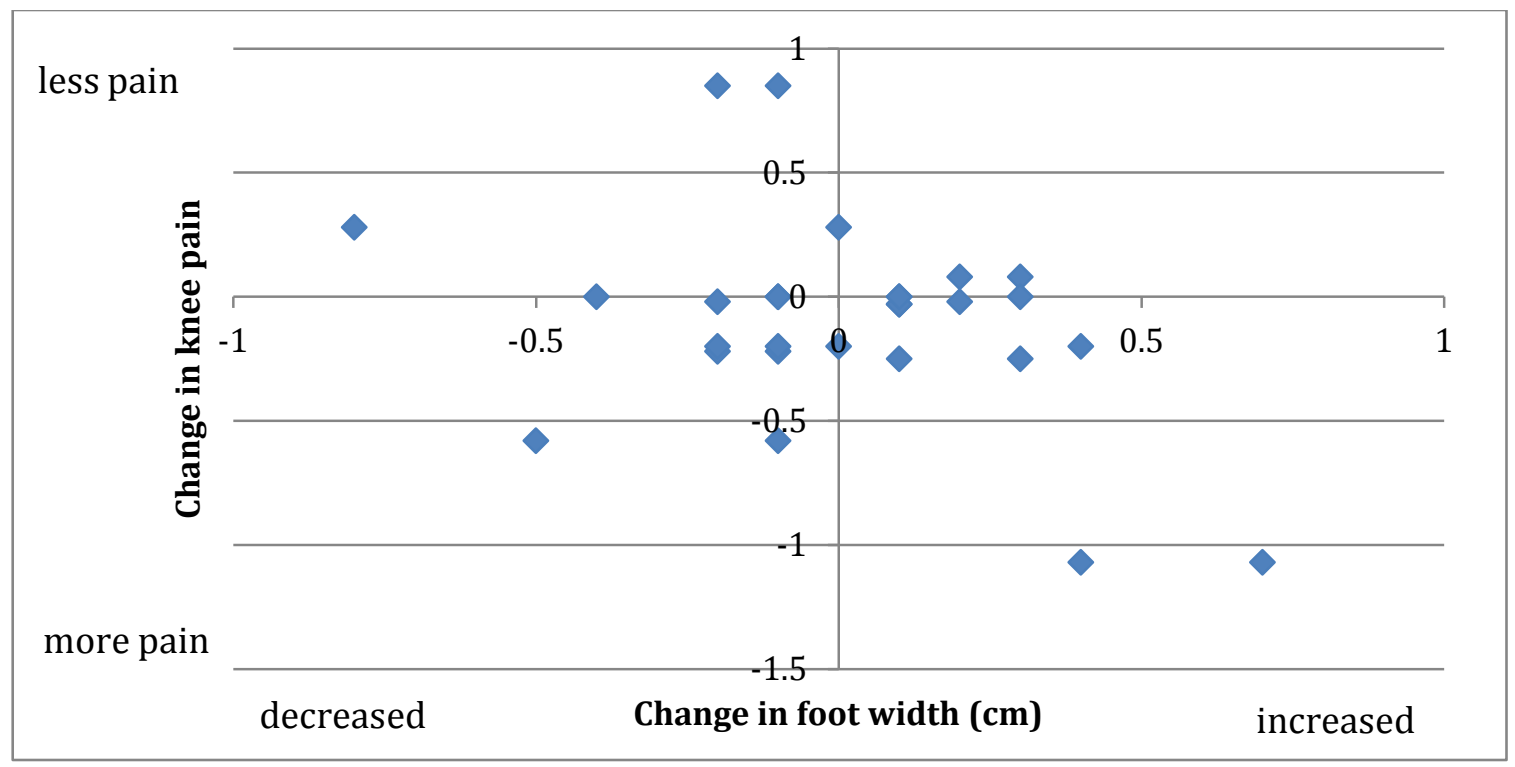

Figure 10. Change in foot width vs. change in knee pain. $r=-0.384$

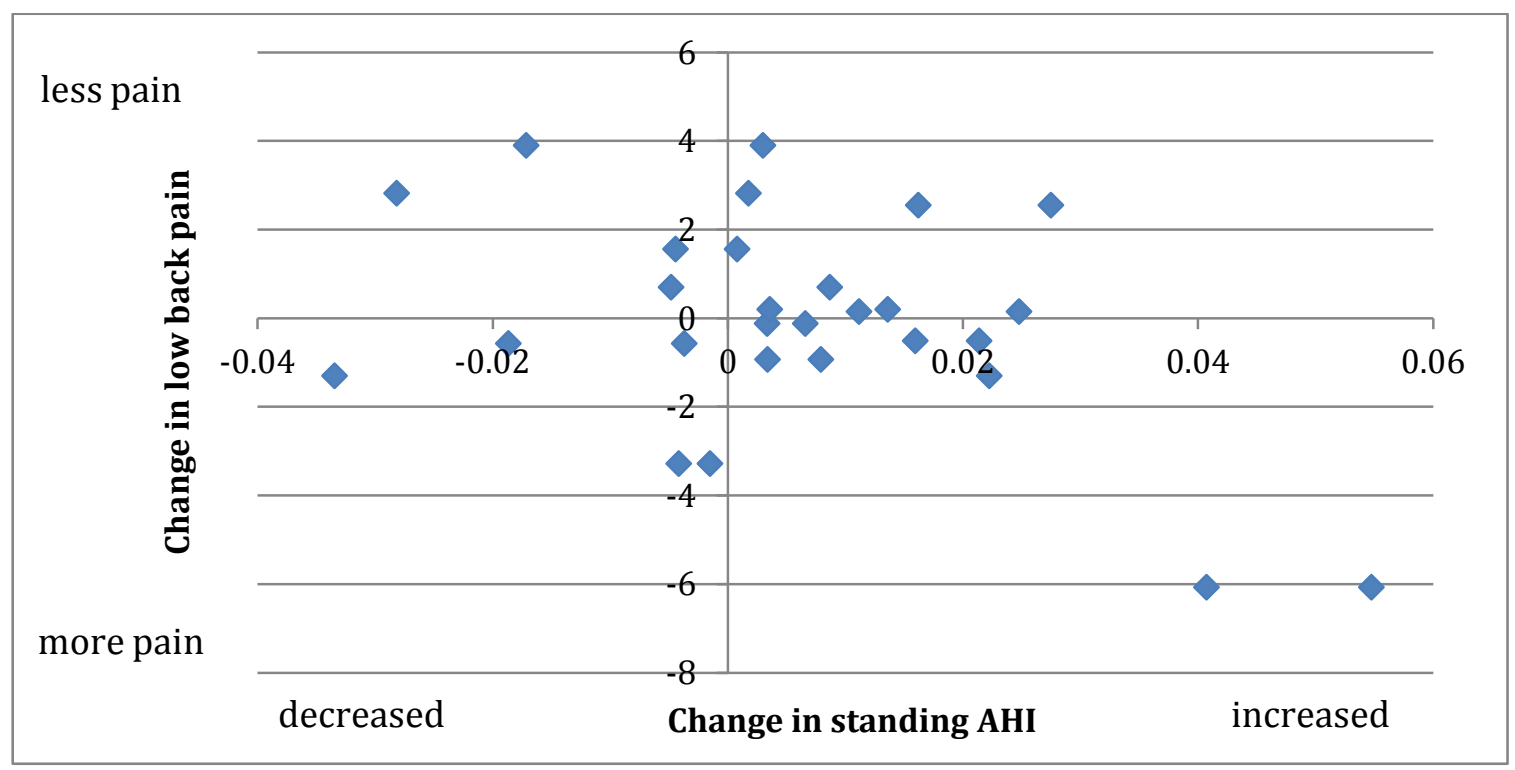

Figure 11. Change in standing AHI vs. change in low back pain. $r=-0.447$ 


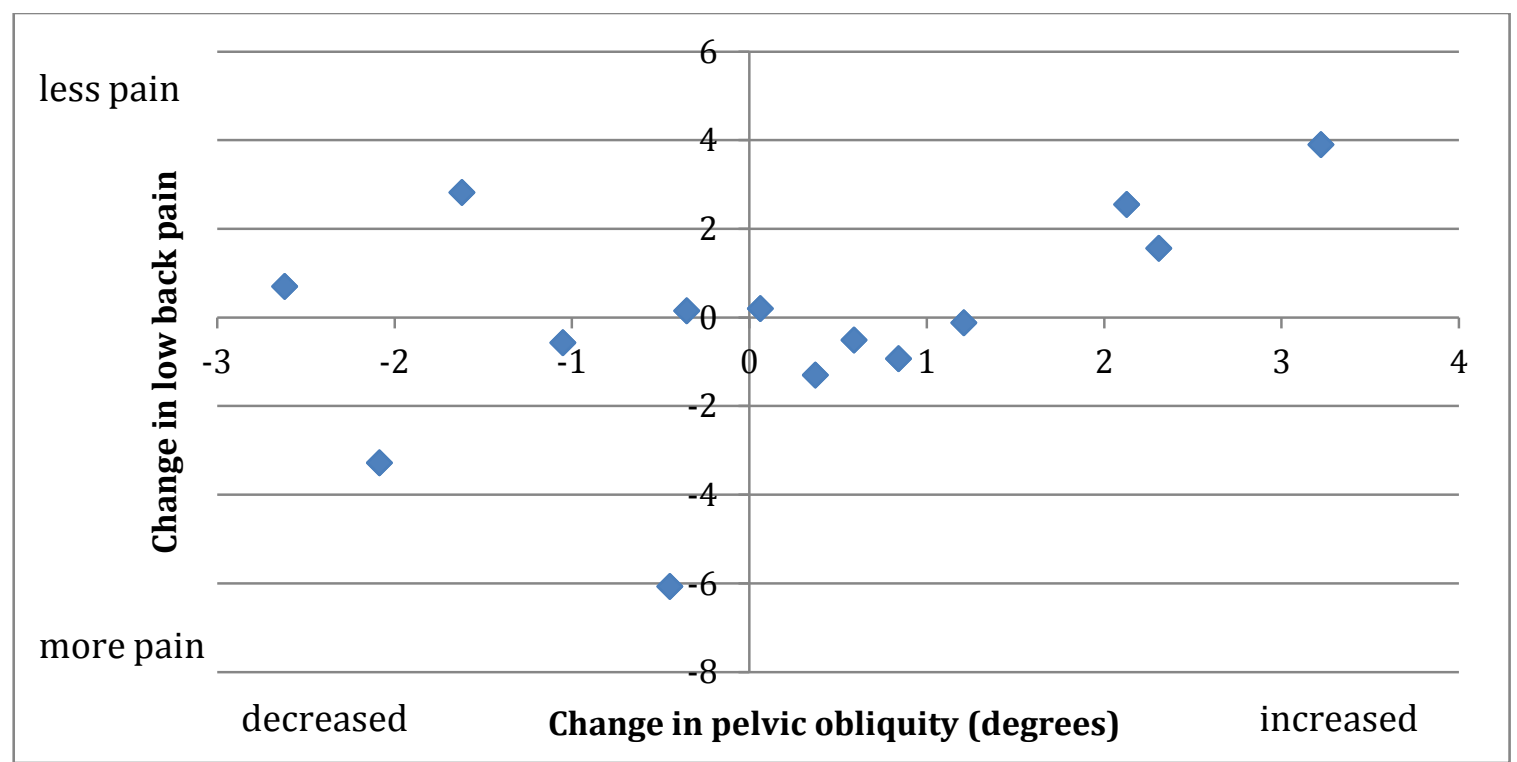

Figure 12. Change in pelvic obliquity vs. change in back pain. $r=0.424$

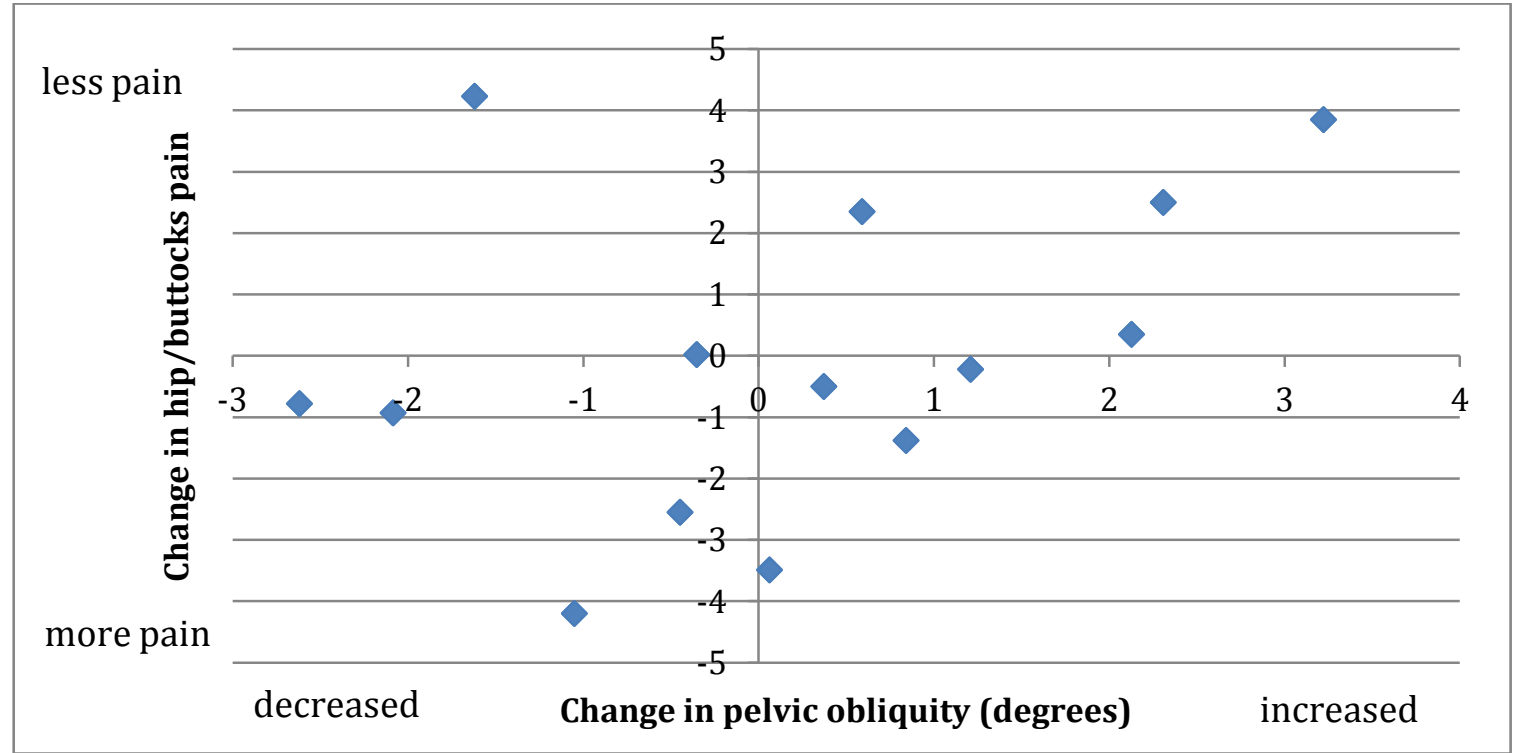

Figure 13. Change in pelvic obliquity vs. change in hip/buttocks pain. $r=0.377$ 
Table 5. Pearson correlation coefficients between changes in lower extremity measurements and changes in pain in participants at their $3^{\text {rd }}$ trimester.

\begin{tabular}{|l|l|l|l|l|l|l|}
\hline & LB & HB & UL & K & LL & FA \\
\hline FL & -0.084 & -0.183 & -0.106 & -0.127 & -0.161 & -0.234 \\
\hline FW & $-0.330^{*}$ & -0.245 & -0.276 & $-0.384^{* *}$ & -0.009 & -0.177 \\
\hline AI & -0.120 & -0.133 & -0.221 & 0.137 & 0.149 & 0.042 \\
\hline $\begin{array}{l}\text { Standing } \\
\text { AHI }\end{array}$ & $-0.447^{*}$ & -0.221 & -0.159 & -0.278 & -0.047 & -0.242 \\
\hline ARI & -0.222 & 0.039 & -0.100 & -0.217 & -0.170 & -0.155 \\
\hline AD & 0.294 & -0.055 & 0.070 & 0.282 & 0.074 & 0.077 \\
\hline RA & 0.037 & 0.147 & -0.083 & -0.060 & -0.201 & -0.136 \\
\hline PO & $0.424 * *$ & $0.377 * *$ & -0.247 & 0.214 & 0.101 & -0.293 \\
\hline
\end{tabular}

$* 0.05<\mathrm{p} \leq 0.1 * * \mathrm{p} \leq 0.05$

\section{Correlation between left/right asymmetry and pain}

Differences between left and right alignment measures and pain were correlated in some cases. Significant correlations were found between left/right difference in AI and pain at the lower leg ( $p=0.09, r=0.224,95 \% \mathrm{CI}:-0.040$ to 0.441$)$, left/right difference in AD and pain the upper leg ( $p=0.02, r=-0.299,95 \%$ CI: -0.514 to -0.035$)$, knee $(p=0.02, r=-0.304,95 \% \mathrm{CI}:-0.499$ to 0.031$)$, lower leg $(\mathrm{p}=0.04$, $\mathrm{r}=0.275,95 \% \mathrm{CI}:-0.493$ to -0.032$)$ and foot/ankle $(\mathrm{p}=0.01, \mathrm{r}=-0.330,95 \% \mathrm{CI}:-0.537$ to -0.103), and left/right difference in ARI and upper leg pain $(p=0.09, r=-0.220$, 95\% CI: -0.447 to -0.007$)$ and foot/ankle pain ( $\mathrm{p}=0.07, \mathrm{r}=-0.236,95 \% \mathrm{CI}:-0.443$ to 0.015). Spearman-Rho correlation coefficients between left/right differences in alignment measures and pain are listed in Table 6. 
Table 6. Spearman-Rho correlation coefficients between left/right differences in alignment measures and pain.

\begin{tabular}{|l|l|l|l|l|l|l|}
\hline & LB & HB & UL & K & LL & FA \\
\hline FL & -0.089 & -0.008 & 0.147 & 0.156 & 0.156 & -0.037 \\
\hline FW & -0.195 & -0.146 & -0.047 & 0.058 & -0.008 & -0.214 \\
\hline AI & -0.114 & -0.087 & 0.024 & 0.038 & 0.224 & 0.170 \\
\hline $\begin{array}{l}\text { Standing } \\
\text { AHI }\end{array}$ & 0.116 & 0.174 & -0.050 & 0.116 & 0.025 & 0.170 \\
\hline ARI & -0.083 & -0.090 & $-0.220^{*}$ & 0.199 & 0.116 & $0.072^{*}$ \\
\hline AD & -0.156 & -0.113 & $-0.299^{* *}$ & $-0.304^{* *}$ & $-0.275^{* *}$ & $-0.330^{* *}$ \\
\hline RA & -0.053 & -0.046 & -0.088 & -0.009 & 0.003 & 0.057 \\
\hline
\end{tabular}

$* 0.05<\mathrm{p} \leq 0.1 * * \mathrm{p} \leq 0.05$

\section{Specific Aim 3: Weighted vs. unweighted conditions}

Specific Aim 3 was to assess changes in lower extremity alignment between the unweighted condition (ie. natural) and the weighted condition (ie. wearing a backpack on the front of the body loaded with the amount of weight expected to be gained during pregnancy). There was an $18 \%$ increase in $\mathrm{AD}(\mathrm{p}=0.001)$ and a $1 \%$ decrease in ARI $(\mathrm{p}=0.002)$ with the added weight. No significant differences were found in any other alignment measures between weighted and unweighted conditions (Table 5).

When control, first trimester, second trimester, and post-partum subjects in the weighted condition were compared to third trimester subjects, differences were found between groups in foot length, foot width, arch index, standing arch height index and pelvic obliquity (Table 7). Specifically, weighted controls had significantly shorter feet than all other groups $(\mathrm{p}=0.000)$. Weighted controls had significantly smaller foot width compared with weighted $2^{\text {nd }}$ trimester, $3^{\text {rd }}$ trimester and weighted post-partum subjects $(\mathrm{p}=0.000)$. Weighted post-partum subjects also had significantly larger foot width than 
weighted $1^{\text {st }}$ trimester $(\mathrm{p}=0.006)$ and $3^{\text {rd }}$ trimester subjects $(\mathrm{p}=0.03)$. Weighted controls had significantly smaller AI measurements than weighted $2^{\text {nd }}$ trimester $(\mathrm{p}=0.02), 3^{\text {rd }}$ trimester ( $\mathrm{p}=0.004)$, and weighted post-partum subjects ( $\mathrm{p}=0.01)$. In standing AHI, weighted controls and $3^{\text {rd }}$ trimester subjects were similar $(\mathrm{p}=0.09)$, and weighted $2^{\text {nd }}$ trimester and weighted post-partum subjects were similar ( $\mathrm{p}=1.0)$. Pelvic obliquity differed between all weighted groups $(\mathrm{p}=0.000)$.

Table 7. Unweighted vs. weighted conditions.

\begin{tabular}{|l|l|l|l|l|l|l|}
\hline & & Control & $\mathbf{1}^{\text {st }}$ trimester & $\mathbf{2}^{\text {nd }}$ trimester & $\mathbf{3}^{\text {rd }}$ trimester & Post-partum \\
\hline \multirow{2}{*}{ FL $(\mathbf{c m})$} & $\mathbf{U}$ & $23.8 \pm 0.8$ & $24.4 \pm 1.0$ & $24.5 \pm 1.1$ & & $24.6 \pm 1.1$ \\
\cline { 2 - 7 } & $\mathbf{W}$ & $23.8 \pm 0.8^{\text {bcde }}$ & $24.5 \pm 0.9^{\mathrm{a}}$ & $24.5 \pm 1.2^{\mathrm{a}}$ & $24.6 \pm 1.3^{\mathrm{a}}$ & $24.7 \pm 1.1^{\mathrm{a}}$ \\
\hline \multirow{2}{*}{ FW $(\mathbf{c m})$} & $\mathbf{U}$ & $8.9 \pm 0.7$ & $9.2 \pm 0.7$ & $9.3 \pm 0.7$ & & $9.3 \pm 0.7$ \\
\cline { 2 - 7 } & $\mathbf{W}$ & $8.9 \pm 0.7^{\text {cde }}$ & $9.1 \pm 0.7^{\mathrm{e}}$ & $9.3 \pm 0.7^{\mathrm{a}}$ & $9.2 \pm 0.8^{\text {ae }}$ & $9.4 \pm 0.7^{\text {abd }}$ \\
\hline \multirow{2}{*}{$\mathbf{A I}$} & $\mathbf{U}$ & $0.23 \pm 0.06$ & $0.23 \pm 0.06$ & $0.25 \pm 0.04$ & & $0.25 \pm 0.04$ \\
\cline { 2 - 7 } & $\mathbf{W}$ & $0.23 \pm 0.06^{\text {cde }}$ & $0.24 \pm 0.05$ & $0.26 \pm 0.04^{\mathrm{a}}$ & $0.26 \pm 0.03^{\mathrm{a}}$ & $0.26 \pm 0.04^{\mathrm{a}}$ \\
\hline \multirow{2}{*}{$\begin{array}{l}\text { Standing } \\
\text { AHI }\end{array}$} & $\mathbf{U}$ & $0.33 \pm 0.02$ & $0.31 \pm 0.02$ & $0.32 \pm 0.03$ & & $0.32 \pm 0.03$ \\
\cline { 2 - 7 } ARI & $\mathbf{W}$ & $0.33 \pm 0.02^{\text {bce }}$ & $0.30 \pm 0.01^{\text {acde }}$ & $0.32 \pm 0.02^{\text {abd }}$ & $0.33 \pm 0.03^{\text {bce }}$ & $0.32 \pm 0.03^{\text {abd }}$ \\
\cline { 2 - 7 } & $\mathbf{U}$ & $0.92 \pm 0.03$ & $0.92 \pm 0.03$ & $0.92 \pm 0.02$ & & $0.92 \pm 0.03$ \\
\hline \multirow{2}{*}{ AD $(\mathbf{c m})$} & $\mathbf{U}$ & $0.92 \pm 0.038$ & $0.90 \pm 0.03^{*}$ & $0.92 \pm 0.03^{*}$ & $0.91 \pm 0.03$ & $0.90 \pm 0.03^{*}$ \\
\cline { 2 - 7 } & $\mathbf{W}$ & $0.44 \pm 0.16^{\mathrm{e}} *$ & $0.37 \pm 0.12$ & $0.39 \pm 0.13$ & & $0.41 \pm 0.16$ \\
\hline \multirow{2}{*}{ RA $\left({ }^{\circ}\right)$} & $\mathbf{U}$ & $183.0 \pm 2.9$ & $183.3 \pm 2.9$ & $183.0 \pm 3.9$ & & $182.9 \pm 4.6$ \\
\cline { 2 - 7 } & $\mathbf{W}$ & $183.3 \pm 2.7$ & $183.3 \pm 2.7$ & $182.9 \pm 3.9$ & $183.0 \pm 3.9$ & $182.8 \pm 4.3$ \\
\cline { 2 - 7 } & $\mathbf{W}$ & $1.9 \pm 1.2^{\text {bcde }}$ & $2.2 \pm 1.1^{\text {acde }}$ & $1.4 \pm 1.1^{\text {abde }}$ & $1.6 \pm 1.1^{\text {abce }}$ & $1.4 \pm 0.8^{\text {abcd }}$ \\
\hline
\end{tabular}

$\mathrm{U}=$ unweighted, $\mathrm{W}=$ weighted. $3^{\text {rd }}$ trimester data are listed under weighted since they carry the same amount of weight.

*significant difference between unweighted and weighted conditions ${ }^{a}$ significant difference from controls. ${ }^{\mathrm{b}}$ significant difference from $1^{\text {st }}$ trimester weighted. ${ }^{c}$ significant difference from $2^{\text {nd }}$ trimester weighted. ${ }^{\mathrm{d}}$ significant difference from $3^{\text {rd }}$ trimester. ${ }^{\mathrm{e}}$ significant difference from post-partum weighted. 


\section{CHAPTER 5: DISCUSSION}

The purpose of this study was to quantify changes in foot and lower extremity anthropometry during pregnancy, and to determine if these changes are related to lower extremity musculoskeletal pain. The rationale was that women often anecdotally report changes in foot shape during pregnancy, which continues post-partum. Some recent literature has supported this observation $(54,59)$. Also, pain during pregnancy has been well documented $(50-52,64)$. However, a relationship between these two factors has not been established. Our hypothesis was that women would experience several changes in lower extremity alignment, leading to increased musculoskeletal pain.

\section{Joint Laxity}

As a measure of joint laxity, all subjects were tested using the Beighton's Ligamentous Laxity Scale at each visit. Previous research has found that peripheral joints increase in mobility, thus one would expect Beighton's scores to increase during pregnancy. However, the opposite was found. Scores were in fact highest in control subjects, and lowest post-partum. However, joint ROM can be influenced by factors other than ligamentous laxity. Swelling may inhibit full range of motion, before ligaments restrict motion. Also, the expanded trunk of women in late pregnancy interferes with bending at the waist.

\section{Specific Aim 1: Changes in anthropometry and alignment}

Specific Aim 1 was to quantify changes in lower extremity anthropometry and alignment over the course of a first pregnancy. It was hypothesized that pregnant women 
would experience an increase in foot length, foot width, arch index, arch drop, rearfoot angle, and pelvic obliquity, as well as a decrease in arch height index and arch rigidity index.

The hypotheses were partially supported. Women had significant increases in foot length and arch index, as well as changes in pelvic obliquity over the course of pregnancy. Findings of increased FL and AI should be interpreted with caution, as they could be affected by swelling of the foot $(2,54)$. Increases in foot length have been found previously (59). Similarly, the increase in AI is supported by existing literature reporting increased area of the foot in contact with the ground $(20,48)$. However, in addition to increased FL, Segal et al. (59) also found increased AD, decreased AHI and decreased ARI from $1^{\text {st }}$ trimester to post-partum. While some of the current results (ARI, AD) trended towards these patterns as well, our changes were not significant. It is possible that with so few subjects in their $1^{\text {st }}$ trimester $(n=4)$ we missed changes occurring from $1^{\text {st }}$ to $3^{\text {rd }}$ trimester, and thus did not see sufficient change to achieve significance. Another possibility is that our $2^{\text {nd }}$ and $3^{\text {rd }}$ trimester measurements were affected by swelling that occurs in late pregnancy $(2,54)$, adding height to the foot unrelated to change in navicular height. Measurements from Segal et al. (59), taken only in the $1^{\text {st }}$ and $3^{\text {rd }}$ trimesters, would not have been affected by this factor.

Also in conflict with our results, Ponnapula and Bonnapart (54) reported increased FW, which we could not confirm. Although our results trended in this direction, we did not achieve significance. A much greater sample size in this study $(n=100)$, may have allowed for significance to be reached (54). It is also possible that 
self-reported data on foot width, as was the case with the study conducted by Ponnapula and Bonnapart (54), is not as accurate as measures taken in a laboratory setting.

Other changes in lower extremity alignment, including RA and PO, have not been investigated previously. Since we found no change in arch characteristics, namely AHI, it makes sense that there was no change in pronation, which can lead to increased RFA (4). Although there were statistically significant differences between groups in PO, posthoc analysis was not able to reveal which groups were significantly different. The pattern did not follow the one we expected. We can only guess that the greater pelvic obliquity seen in controls and first trimester subjects are due to factors unrelated to pregnancy.

\section{Specific Aim 2: Relationship between anthropometry and alignment changes and pain}

Specific aim 2 was to determine the relationship between lower extremity alignment changes and musculoskeletal pain of the lower extremity. It was hypothesized that malalignment in the pelvis and foot would be related to the severity of lower extremity pain in both the pregnant women and the control group, and that the pregnant women would experience changes in alignment that are related to increased pain over the course of a first pregnancy.

\section{Differences in pain between groups}

As hypothesized, changes were found in pain over the course of a first pregnancy. Significant differences in pain were seen at the low back, hip/buttocks, upper leg, knee and lower leg between groups. This makes sense given previous literature finding the 
there was greater incidence of pain in pregnant women at the low back $(51,52)$ and pelvis (50). However, lack of significant changes in pain at the foot/ankle conflicts with previous reports of increased incidence of foot pain in pregnant women (64). Perhaps with a greater sample size, we would find significant changes, as foot/ankle pain scores did trend downwards over the course of pregnancy.

It should be noted that despite worsening pain scores, we did not conclude that our pregnant group was actually in pain, as did previous studies $(50-52,64)$. It is difficult to determine what qualifies as pain, as different people may have different thresholds for pain. A post-hoc Spearman correlation analysis was performed to see if pain scores at different locations on the body in the same subject were related. Several scores were significantly correlated (Table 7). This could be due to differences between subjects in perceptions of pain (ie. If a subject has a lower threshold for pain, they are more likely to report lower pain scores at all locations on the body). However, in previous research on running injuries (19), a score less than 7 on the VAS scale was considered pain, so this is the standard we used. No groups in our study fell below this pain level at any location on the body.

Table 7. Correlation between pain scores.

\begin{tabular}{|l|l|l|l|l|l|}
\hline & Hip/buttocks & $\begin{array}{l}\text { Upper } \\
\text { leg }\end{array}$ & Knee & $\begin{array}{l}\text { Lower } \\
\text { leg }\end{array}$ & Foot/ankle \\
\hline Low back & $0.523^{* *}$ & $0.332^{* *}$ & 0.016 & 0.062 & $0.313^{* *}$ \\
\hline Hip/Buttocks & & $.0360^{* *}$ & $0.181^{* *}$ & $0.273^{* *}$ & $0.184^{* *}$ \\
\hline Upper leg & & & $0.624^{* *}$ & $0.748^{* *}$ & $0.318^{* *}$ \\
\hline Knee & & & & $0.558^{* *}$ & $0.224^{* *}$ \\
\hline Lower Leg & & & & & $0.414^{* *}$ \\
\hline
\end{tabular}

$* * \mathrm{p}<0.05$ 


\section{Correlation between pain and anthropometry/alignment}

Several lower extremity alignment measures were correlated with pain, however this correlation only followed the expected direction in 3 of 5 cases. AI was positively correlated with upper leg $(r=0.175)$ and knee pain $(p=0.287)$ scores. Higher values of AI are due to increased area of the midfoot in contact with the ground, indicating a lower arch. Therefore, a low arch was associated with less pain at the upper leg and knee, and a high arch was associated with no pain. This conflicts with the hypothesis that women pregnant women would experience a decrease in arch height, concomitant with worsening pain. However, previous research in runners supports our results (11). Runners with anterior knee pain had lower arch index values compared with runners without pain (11). This relationship between high arches and knee pain is arguable. Williams, McClay and Hamill (66) found that runners with low arch were predisposed to knee injuries. However, a similar study in professional runners found that there was no relationship between arch height and knee injury (44). In the general population, Hegedus, Fiander and Wright (27) found no relationship between arch height and pain in people with lower extremity impairments.

As hypothesized, we did find that ARI and AD, measures of arch flexibility, were positively correlated with pain at the low back ( $\mathrm{r}=0.203$ and $\mathrm{r}=-0.213$, respectively) and at the foot/ankle ( $r=0.255$ and $r=-0.231$, respectively). In both cases, more flexible arches were associated with worse pain. We expected this relationship, given increased joint mobility during pregnancy (5), along with increased pain $(50-52,64)$. To our knowledge, no previous research has examined the influence of arch flexibility on musculoskeletal pain. 
The relationship between rearfoot angle and pain also followed the expected direction. Increasing degrees of rearfoot angle were associated with worsening pain in the foot/ankle $(\mathrm{r}=0.169)$. There has been much interest in the role of pronation in injury in previous literature. The results have been conflicting. Similar to the present results, pronation has been associated with foot pain in women(39) as well as low back pain in the general population (40). However, foot pronation is not associated with general injury risk in female soccer players (47), or in recreational runners (46).

Finally, the relationship between PO and pain was opposite to what we expected. It was hypothesized that increased degree of pelvic obliquity would be associated with worse pain, however in this case it was associated with improved foot/ankle pain scores. Given increased PO was found in controls in Specific Aim 1, this correlation now makes sense. If controls have PO for reasons other than pregnancy, but are in less pain, we can assume that musculoskeletal pain is influenced strongly by factors other than PO. There is no research correlating PO with foot/ankle pain. Some research has examined the relationship with back pain, but no correlation was found (14).

In the case of arch height, pronation, and pelvic obliquity, current literature, along with the present results, demonstrate that musculoskeletal pain of the lower extremity is a complex problem, likely influenced by multiple factors. Thus it is difficult to differentiate the role of between alignment and anthropometry factors influenced by pregnancy, and other physiological and environmental factors that may be contributing to pain. 


\section{Correlation between changes in anthropometry/alignment and pain}

A few changes in lower extremity measurements were correlated with changes in pain level during pregnancy. Specifically, increased FW was negatively correlated with pain at the low back and knee, standing AHI was negatively correlated with change in pain at the low back, and change in PO was positively correlated with change in pain at the low back and hip/buttocks.

The correlation between change in FW and change in knee pain was what was expected. It was hypothesized that increase would be secondary to a decrease in arch height, and therefore associated with worsening pain. This relationship held true. This agrees with the literature showing that lower arches are associated with knee pain in runners (66).

However, the correlation between standing AHI and change in pain was opposite to what was expected. In this case, a greater decrease in arch height from $2^{\text {nd }}$ to $3^{\text {rd }}$ trimester was associated with improved pain scores at the low back. The hypothesized change has not been supported in the literature. The Framingham Foot Study, an extensive investigation into the relationship between foot measures and lower extremity pain, found no relationship between foot posture and low back pain (41). The unexpected correlation may be explained by the fact that in a young population, only severe pes planus is associated with knee and back pain (32). Therefore, perhaps the moderate arch heights found in our study are not low enough to cause pain.

Also contrary to expectations, change in PO was weakly but positively correlated with change in low back and hip/buttocks pain. Women experienced a slight increase in PO from $2^{\text {nd }}$ to $3^{\text {rd }}$ trimester, associated with improved pain at the low back. It was 
expected that increased PO to be associated with worse pain. However, previous research has found no correlation between PO and pain (14). Further, correcting pelvic obliquity through use of heel lifts is not effective in treating back pain in all patients (23). The small change in pelvic obliquity found in our subjects $\left(0.2^{\circ}\right)$, is not significant. Thus the change may not be sufficient to establish an accurate correlation.

\section{Correlation between left right asymmetry and pain}

It has been suggested based on clinical observation that asymmetry in alignment measures may contribute to musculoskeletal pain, however this relationship has not been previously investigated. These results support this observation. Specifically, asymmetry in $\mathrm{AD}$ was negatively correlated with pain at the upper leg, knee, lower leg and foot/ankle. Asymmetry in ARI was negatively correlated with pain at the upper leg and foot/ankle. Contrary to expectation, asymmetry in AI was positively correlated with pain at the lower leg. However, if swelling did indeed influence AI measurements, then this correlation may be skewed. To date, there is a paucity of research on the effect of asymmetry in alignment on pain and injury with which to compare the present results.

\section{Specific Aim 3: Weighted vs. unweighted conditions}

Specific Aim 3 was to examine the effect of added weight on lower extremity measurements in pregnant women and controls. It was hypothesized that pregnancy, due to the effect of hormonal changes influencing ligamentous laxity, would have a greater effect on these measurements than added weight alone.

This hypothesis was partially supported by the results. The same number of significantly different measures was found between weighted and unweighted conditions 
in control, $1^{\text {st }}$ trimester, $2^{\text {nd }}$ trimester and post-partum subjects, as between these groups and $3^{\text {rd }}$ trimester subjects. However, the changes due to added weight and the changes seen with the hormonal fluctuations of the $3^{\text {rd }}$ trimester of pregnancy are different. Weight alone affected AD and ARI, while the combined factors of pregnancy affected FL and AI. Certainly, added weight does have some effect on foot shape. Tsung et al. (63) measured foot shape characteristics in 8 normal adults ( 3 males, 5 females) under three conditions: full weight-bearing (standing with all weight on one foot, semi-weight bearing (standing with half body weight on one foot), and non-weight bearing (sitting without bearing any weight on the feet). They found increased foot length and foot width, as well as decreased arch height with increased weight bearing in non-weightbearing, half-weight bearing and full-weight bearing conditions (63). No changes were seen in FL and FW with added weight likely because the average amount weight gained during pregnancy $(12.6 \mathrm{~kg})$ is much less that $1 / 2$ or full body-weight. Therefore, it can be assumed that $12.6 \mathrm{~kg}$ is sufficient to alter $\mathrm{AD}$ and $\mathrm{ARI}$, but not FL or AI, without the added influence of hormones.

Further, we found differences in FL, FW, AI, AHI and PO between measures from weighted controls, weighted $1^{\text {st }}$ and $2^{\text {nd }}$ trimester subjects, $3^{\text {rd }}$ trimester subjects, and weighted post-partum subjects. If added weight was indeed the primary factor mediating changes in foot shape, it would be expected that these groups would have similar measurements, as they all carried a similar amount of weight $\left(1^{\text {st }}\right.$ and $2^{\text {nd }}$ trimester subjects were weighted with $12.6 \mathrm{~kg}$, however in this study the mean weight gain was 16.3kg. Control and post-partum subjects were matched exactly to $3^{\text {rd }}$ trimester weight). Since the groups displayed different lower extremity characteristics, this suggests that 
other factors involved with pregnancy, such as altered hormones, may play a role in lower extremity alignment changes.

This idea is supported by the literature finding increased ligamentous laxity related to the hormone Relaxin (5). Further compounding the effect of Relaxin may be increased sex steroids, progesterone and estrogen, which may upregulate relaxin receptors in tendons and ligaments (10). It should be noted that post-partum hormones levels may be affected by nursing, and therefore levels of hormones related to pregnancy, such as Relaxin, may not return to baseline in women who choose to breast-feed.

\section{Limitations}

Several limitations exist in this study. First, use of control subjects as a measure of pre-pregnancy lower extremity alignment is not ideal. Even though control subjects were matched to pregnant subjects based on weight, they are not necessarily musculoskeletally similar to their pregnant match, but may in fact have innate differences in structure, unrelated to changes during pregnancy. FL and FW are particular examples of this limitation. Unfortunately finding participants before they became pregnant was not feasible.

Second, since there were no data to indicate whether pain was experienced on the left or right side of the body, we pooled measurement data between the left and right feet. However, if measurements from each side of the body were associated to pain in the same side, we may have been able to find more significant correlation.

Third, pregnant women are known to experience swelling of the lower extremity, especially during the $3^{\text {rd }}$ trimester $(2,54)$. From weeks 13 to 35 , feet swell an average of 57.2mL (2). This swelling may have affected our measurements, making the foot seem 
longer, wider or taller, regardless of actual structural changes in the foot. It was our hope that the calipers and anthropometer used, being of hard material, would press through any swelling to get an accurate measure of true foot length, foot width and arch height, however we cannot be certain that the measures were unaffected.

Similarly, time of day may affect foot volume. Over the course of four hours, foot volume has been found to increase $4 \%$ in normal, non-pregnant people (36). In order to accommodate participants' schedules and appointments at the obstetrics clinic, it was not possible to control for time of day in taking our measurements.

Finally, the small sample size of $1^{\text {st }}$ trimester subjects $(n=4)$ limits the power of this study to determine differences between this group, the control, $2^{\text {nd }}$ trimester, $3^{\text {rd }}$ trimester and post-partum groups. Data from each of the four subjects at this time carry much more statistical weight than their measurements at later time points, or controls. Therefore outliers in the $1^{\text {st }}$ trimester group skew data to a greater degree than subjects in other groups, making the means difficult to compare.

\section{Future research}

The topic of lower extremity alignment changes during pregnancy is one that requires further exploration before firm conclusions can be made. Specifically, pregnant women who do experience pain should be compared to those who do not, in addition to a non-pregnant control group. Hopefully, with greater differences between groups, a clearer correlation could be seen in terms of lower extremity alignment and pain.

Future studies should also include pregnant women who have had a pregnancy/pregnancies previous to the study, to determine if changes in alignment and pain accumulate over multiple pregnancies. 
Should a correlation indeed be established, future work could look into preventing these changes, with the goal of also preventing musculoskeletal pain during pregnancy. Possible treatments may include use of orthotics, strengthening exercises to help support and maintain foot and lower extremity structure, or therapy to maintain alignment.

\section{Conclusions}

Over the course of a first pregnancy, women experience changes in lower extremity anthropometry, including increased foot length, increased arch index and changes in pelvic obliquity. These changes are independent of added weight alone, thus are likely mediated by hormonal factors. Also, levels of pain worsen at the low back, hip/buttocks and lower leg over the course of pregnancy. Measures of lower extremity alignment, namely AHI, ARI, AD, RA and PO are related to musculoskeletal pain in the lower extremity. Further, changes in AHI and PO during pregnancy are related to change in pain level. This information may be of use to clinicians treating pregnant patients presenting with low back, leg and foot pain. 


\section{REFERENCES}

1. Albert H, Godskesen M, Westergaard JG, Chard T, Gunn L. Circulating levels of relaxin are normal in pregnant women with pelvic pain. Eur J Obstet Gynecol Reprod Biol. 1997; 74(1):1922.

2. Alvarez R, Stokes IA, Asprinio DE, Trevino S, Braun T. Dimensional changes of the feet in pregnancy. J Bone Joint Surg Am. 1988; 70(2):271-4.

3. Bird AR, Menz HB, Hyde CC. The effect of pregnancy on footprint parameters. A prospective investigation. J Am Podiatr Med Assoc. 1999; 89(8):405-9.

4. Block RA, Hess LA, Timpano EV, Serlo C. Physiologic changes in the foot during pregnancy. J Am Podiatr Med Assoc. 1985; 75(6):297-9.

5. Calguneri M, Bird HA, Wright V. Changes in joint laxity occurring during pregnancy. Ann Rheum Dis. 1982; 41(2):126-8.

6. Cavanagh PR, Rodgers MM. The arch index: a useful measure from footprints. J Biomech. 1987; 20(5):547-51.

7. Charpentier K, Leboucher J, Lawani M, Toumi H, Dumas G-, Pinti A. Back pain during pregnancy and living conditions - a comparison between Beninese and Canadian women. Annals of Physical and Rehabilitation Medicine(0).

8. Clarke T, E Frederick, C Hamill. The study of rearfoot movement in running. 1984. 
9. Conrad KP. Maternal vasodilation in pregnancy: the emerging role of relaxin. Am J Physiol Regul Integr Comp Physiol. 2011; 301(2):R267-75.

10. Dehghan F, Muniandy S, Yusof A, Salleh N. Sex-steroid regulation of relaxin receptor isoforms (RXFP1 \& RXFP2) expression in the patellar tendon and lateral collateral ligament of female WKY rats. Int J Med Sci. 2014; 11(2):180-91.

11. Duffey MJ, Martin DF, Cannon DW, Craven T, Messier SP. Etiologic factors associated with anterior knee pain in distance runners. Med Sci Sports Exerc. 2000; 32(11):1825-32.

12. Dumas GA, Reid JG, Wolfe LA, Griffin MP, McGrath MJ. Exercise, posture, and back pain during pregnancy. Clin Biomech (Bristol, Avon). 1995; 10(2):104-9.

13. Enders LA, Berger K, Chambers AJ, Redfern R and McCrory JL. Biomechanical evidence of waddling during pregnancy. In: Proceedings of the BMES 2009 Annual Fall Scientific Meeting; October 7-10, 2009; 2009.

14. Fann AV. The prevalence of postural asymmetry in people with and without chronic low back pain. Arch Phys Med Rehabil. 2002; 83(12):1736-8.

15. Fast A, Weiss L, Ducommun EJ, Medina E, Butler JG. Low-back pain in pregnancy. Abdominal muscles, sit-up performance, and back pain. Spine (Phila Pa 1976). 1990; 15(1):2830.

16. Fell DB, Joseph KS, Armson BA, Dodds L. The impact of pregnancy on physical activity level. Matern Child Health J. 2009; 13(5):597-603.

17. Foti T, Davids JR, Bagley A. A biomechanical analysis of gait during pregnancy. J Bone Joint Surg Am. 2000; 82(5):625-32. 
18. Franklin ME, Conner-Kerr T. An analysis of posture and back pain in the first and third trimesters of pregnancy. J Orthop Sports Phys Ther. 1998; 28(3):133-8.

19. Galbreath KM, KD Harrison, JL McCrory. The influence of arch type on injury in minimallyshod runners. Medicine \& Science in Sports \& Exercise. 2014; 46(5): p. S318.

20. Gaymer C, Whalley H, Achten J, Vatish M, Costa ML. Midfoot plantar pressure significantly increases during late gestation. Foot (Edinb). 2009; 19(2):114-6.

21. Gilleard WL, Crosbie J, Smith R. Static trunk posture in sitting and standing during pregnancy and early postpartum. Arch Phys Med Rehabil. 2002; 83(12):1739-44.

22. Gilleard WL, Brown JM. Structure and function of the abdominal muscles in primigravid subjects during pregnancy and the immediate postbirth period. Phys Ther. 1996; 76(7):750-62.

23. Gofton JP. Persistent low back pain and leg length disparity. J Rheumatol. 1985; 12(4):74750.

24. Goldsmith LT, Weiss G. Relaxin in Human Pregnancy. Ann N Y Acad Sci. 2009; 1160(1):130-5.

25. Gutke A, Ostgaard HC, Oberg B. Association between muscle function and low back pain in relation to pregnancy. J Rehabil Med. 2008; 40(4):304-11.

26. Gutke A, Sjodahl J, Oberg B. Specific muscle stabilizing as home exercises for persistent pelvic girdle pain after pregnancy: a randomized, controlled clinical trial. J Rehabil Med. 2010; 42(10):929-35. 
27. Hegedus EJ, Cook C, Fiander C, Wright A. Measures of arch height and their relationship to pain and dysfunction in people with lower limb impairments. Physiother Res Int. 2010; 15(3):160-6.

28. Kashanian M, Akbari Z, Alizadeh MH. The effect of exercise on back pain and lordosis in pregnant women. International Journal of Gynecology \& Obstetrics. 2009; 107(2):160-1.

29. Kaufman KR, Brodine SK, Shaffer RA, Johnson CW, Cullison TR. The Effect of Foot Structure and Range of Motion on Musculoskeletal Overuse Injuries. The American Journal of Sports Medicine. 1999; 27(5):585-93.

30. Kluge J, Hall D, Louw Q, Theron G, Grove D. Specific exercises to treat pregnancy-related low back pain in a South African population. Int J Gynaecol Obstet. 2011; 113(3):187-91.

31. Kosashvili Y, Fridman T, Backstein D, Safir O, Bar Ziv Y. The correlation between pes planus and anterior knee or intermittent low back pain. Foot Ankle Int. 2008; 29(9):910-3.

32. Kosashvili Y, Fridman T, Backstein D, Safir O, Bar Ziv Y. The correlation between pes planus and anterior knee or intermittent low back pain. Foot Ankle Int. 2008; 29(9):910-3.

33. Kristiansson P, Svardsudd K, von Schoultz B. Serum relaxin, symphyseal pain, and back pain during pregnancy. Am J Obstet Gynecol. 1996; 175(5):1342-7.

34. Kristiansson P, Svärdsudd K, von Schoultz B. Reproductive hormones and aminoterminal propeptide of type III procollagen in serum as early markers of pelvic pain during late pregnancy. Obstet Gynecol. 1999; 180(1):128-34.

35. MacLennan AH, Nicolson R, Green RC, Bath M. Serum relaxin and pelvic pain of pregnancy. Lancet. 1986; 2(8501):243-5. 
36. Mayrovitz HN, Sims N, Litwin B, Pfister S. Foot volume estimates based on a geometric algorithm in comparison to water displacement. Lymphology. 2005; 38(1):20-7.

37. McCrory JL, AJ Chambers, A Daftary, MS Redfern. The effect of pregnancy on torso kinematics during gait. Medicine and Science in Sports and Exercise. 2012; 44(5): p. 574.

38. McCrory JL, Chambers AJ, Daftary A, Redfern MS. Dynamic postural stability during advancing pregnancy. $J$ Biomech. 2010; 43(12):2434-9.

39. Menz HB, Dufour AB, Riskowski JL, Hillstrom HJ, Hannan MT. Association of planus foot posture and pronated foot function with foot pain: the Framingham foot study. Arthritis Care Res (Hoboken). 2013; 65(12):1991-9.

40. Menz HB, Dufour AB, Riskowski JL, Hillstrom HJ, Hannan MT. Foot posture, foot function and low back pain: the Framingham Foot Study. Rheumatology (Oxford). 2013; 52(12):2275-82.

41. Menz HB, Dufour AB, Riskowski JL, Hillstrom HJ, Hannan MT. Foot posture, foot function and low back pain: the Framingham Foot Study. Rheumatology (Oxford). 2013; 52(12):2275-82.

42. Moore K, Dumas G, Reid J. Postural changes associated with pregnancy and their relationship with low-back pain. Clinical biomechanics (Bristol, Avon). 1990; 5(169).

43. Mørkved S, Salvesen KÅ, Schei B, Lydersen S, Bø K. Does group training during pregnancy prevent lumbopelvic pain? A randomized clinical trial. Acta Obstet Gynecol Scand. 2007; 86(3):276-82.

44. Nakhaee Z, Rahimi A, Abaee M, Rezasoltani A, Kalantari KK. The relationship between the height of the medial longitudinal arch (MLA) and the ankle and knee injuries in professional runners. Foot (Edinb). 2008; 18(2):84-90. 
45. Naqvi T, Duong TT, Hashem G, Shiga M, Zhang Q, Kapila S. Relaxin's induction of metalloproteinases is associated with the loss of collagen and glycosaminoglycans in synovial joint fibrocartilaginous explants. Arthritis Res Ther. 2005; 7(1):R1-11.

46. Nielsen RO, Buist I, Parner ET, Nohr EA, Sorensen H, Lind M, Rasmussen S. Foot pronation is not associated with increased injury risk in novice runners wearing a neutral shoe: a 1-year prospective cohort study. Br J Sports Med. 2014; 48(6):440-7.

47. Nilstad A, Andersen TE, Bahr R, Holme I, Steffen K. Risk factors for lower extremity injuries in elite female soccer players. Am J Sports Med. 2014; 42(4):940-8.

48. Nyska M, Sofer D, Porat A, Howard CB, Levi A, Meizner I. Planter foot pressures in pregnant women. Isr J Med Sci. 1997; 33(2):139-46.

49. Okanishi N, Kito N, Akiyama M, Yamamoto M. Spinal curvature and characteristics of postural change in pregnant women. Acta Obstet Gynecol Scand. 2012.

50. Ostgaard HC, Andersson GB, Karlsson K. Prevalence of back pain in pregnancy. Spine (Phila Pa 1976). 1991; 16(5):549-52.

51. Ostgaard HC, Roos-Hansson E, Zetherstrom G. Regression of back and posterior pelvic pain after pregnancy. Spine (Phila Pa 1976). 1996; 21(23):2777-80.

52. Padua L, Padua R, Bondi R, Ceccarelli E, Caliandro P, D'Amico P, Mazza O, Tonali P. Patient-oriented assessment of back pain in pregnancy. Eur Spine J. 2002; 11(3):272-5.

53. Pinto RZ, Souza TR, Trede RG, Kirkwood RN, Figueiredo EM, Fonseca ST. Bilateral and unilateral increases in calcaneal eversion affect pelvic alignment in standing position. Man Ther. 2008; 13(6):513-9. 
54. Ponnapula P, Boberg JS. Lower extremity changes experienced during pregnancy. J Foot Ankle Surg. 2010; 49(5):452-8.

55. Robinson DP, Klein SL. Pregnancy and pregnancy-associated hormones alter immune responses and disease pathogenesis. $\operatorname{Horm} \operatorname{Behav}(0)$.

56. Robinson HS, Eskild A, Heiberg E, Eberhard-Gran M. Pelvic girdle pain in pregnancy: The impact on function. Acta Obstet Gynecol Scand. 2006; 85(2):160-4.

57. Rothenberg RJ. Rheumatic disease aspects of leg length inequality. Semin Arthritis Rheum. $1988 ; 17(3): 196-205$.

58. Schauberger CW, Rooney BL, Goldsmith L, Shenton D, Silva PD, Schaper A. Peripheral joint laxity increases in pregnancy but does not correlate with serum relaxin levels. Obstet Gynecol. 1996; 174(2):667-71.

59. Segal NA, Boyer ER, Teran-Yengle P, Glass NA, Hillstrom HJ, Yack HJ. Pregnancy leads to lasting changes in foot structure. Am J Phys Med Rehabil. 2013; 92(3):232-40.

60. Stafne SN, Salvesen KA, Romundstad PR, Stuge B, Morkved S. Does regular exercise during pregnancy influence lumbopelvic pain? A randomized controlled trial. Acta Obstet Gynecol Scand. 2012.

61. Stuber J, Zech S, Bay R, Qazzaz A, Richter M. Normative data of the Visual Analogue Scale Foot and Ankle (VAS FA) for pathological conditions. Foot Ankle Surg. 2011; 17(3):166-72.

62. Stuge B, Veierod MB, Laerum E, Vollestad N. The efficacy of a treatment program focusing on specific stabilizing exercises for pelvic girdle pain after pregnancy: a two-year follow-up of a randomized clinical trial. Spine (Phila Pa 1976). 2004; 29(10):E197-203. 
63. Tsung BY, Zhang M, Fan YB, Boone DA. Quantitative comparison of plantar foot shapes under different weight-bearing conditions. J Rehabil Res Dev. 2003; 40(6):517-26.

64. Vullo VJ, Richardson JK, Hurvitz EA. Hip, knee, and foot pain during pregnancy and the postpartum period. J Fam Pract. 1996; 43(1):63-8.

65. Weiss G, O'Byrne EM, Steinetz BG. Relaxin: a product of the human corpus luteum of pregnancy. Science. 1976; 194(4268):948-9.

66. Williams DS,3rd, McClay IS, Hamill J. Arch structure and injury patterns in runners. Clin Biomech (Bristol, Avon). 2001; 16(4):341-7.

67. Wu WH, Meijer OG, Bruijn SM, Hu H, van Dieen JH, Lamoth CJ, van Royen BJ, Beek PJ. Gait in Pregnancy-related Pelvic girdle Pain: amplitudes, timing, and coordination of horizontal trunk rotations. Eur Spine J. 2008; 17(9):1160-9. 


\section{APPENDIX A: Foot Alignment in Pregnancy Telephone Screening Script and Screening Questionnaire}

Upon answering a phone call from a potential subject:

"Hello. Thank you for calling for information about study. Let me tell you more about it so you can decide if you would like to participate. The purpose of the study is to determine the relationship between foot structure and back pain during pregnancy. Half of pregnant women experience back pain, however the cause of this pain is not currently known.

As part of the study, we take a few different types of measurements. We will first ask you to fill out 3 questionnaires about any foot and back pain you experience as well as your physical activity and lifestyle. Next we will take a footprint to assess your foot arch. Then, we will take a picture of your foot in sitting and standing positions to further assess your foot arch. Another photograph will be taken with tape markers placed on each hip to assess your hip alignment. Finally, we will take a picture of the back of your leg, to measure the angle of your ankle while standing. None of the tests will be physically strenuous.

The entire testing session, from the time you walk in the door until you are finished, should last approximately thirty minutes. Are you still interested in participating in the study?"

If the subject agrees, then proceed to the next paragraph:

"In order to determine if you are eligible to participate in the study, I need to ask you a series of questions. The questions will take approximately 10 minutes to ask. Is this okay? Please ask me about any questions that are not clear to you. “

1) What is your age? (If not between 18 and 45, subject is ineligible)

2) Do you have diabetes? Yes $\square \quad$ No $\square$ If subject answered "yes", then ask the following question:

Do you have to take insulin for it? Yes $\square$ No $\square$

If subject answered "yes", then subject is ineligible.

3) Do you have any medical condition that effects your sensation (or perception of touch or movement)? Yes $\square$ No $\square$

If subject answered "yes", then subject is ineligible

4) Have you ever fractured your leg or foot? $\quad$ Yes $\square$ No $\square$ If subject answered "yes", then subject is ineligible

5) Have your ever had a torn ligament in your leg or surgery to fix one? $\quad$ Yes $\square$ No $\square$

If subject answered "yes", then subject is ineligible 
6) Have your sprained your ankle or knee within the past year? $\quad$ Yes $\square$ No $\square$ If subject answered "yes", then subject is ineligible

7) Do you smoke? Yes $\square$ No If subject answered "yes", then subject is ineligible

8) Do you currently take any medications? Yes $\square \quad$ No $\square$ If subject answered "yes", then list here:

If medication would interfere with neurological, musculoskeletal, or cognitive function, then subject is ineligible.

9) Are you pregnant? $\quad$ Yes $\square$ No $\square$

10) If subject is pregnant, ask : Do you have toxemia? Yes $\square \quad$ No $\square$ If subject answered "yes", then subject is ineligible

11) For both pregnant and non-pregnant subjects, ask: Have you been pregnant previously? Yes $\square \quad$ No $\square$ If subject answered "yes", then the subject is ineligible

If subject is eligible to complete the study, state the following:

"You meet all of our criteria for including you in the study. Would you like to schedule a time for you to come into the lab to do the tests that I explained earlier?"

Proceed to scheduling the subject....

If subject is not eligible to complete the study, state the following:

"Based on your answer to the question about (state question topic here), you are not eligible to complete in the study. Thank you for calling about the study though. There may be future studies for which you are qualified. My paperwork from our phone conversation will be destroyed so that no one else will see your data." 


\section{APPENDIX B: Consent and Information Form}

OMR ICF

Principal Investigator: McCrory, Jean

Department: Tracking Number:

MEDICINE - Exercise Physiology

H-23586

\section{Study Title:}

Relationship between changes in foot and pelvis alignment and the incidence of lumbar, posterior pelvis, and foot pain during pregnancy.

\section{Co-Investigator(s):}

Thomas, Krystal, Harrison, Kathryn,

\section{Sponsor}

\section{Contact Persons}

In the event you experience any side effects or injury related to this research, you should contact Dr.Jean McCrory at 304/293-0442. (After hours contact Dr. McCrory at 724/5544955.)

If you have any questions, concerns, or complaints about this research, you can contact Dr. Stephen Alway at 304/293-0772

For information regarding your rights as a research subject, you may contact the Office of Research Compliance at 304/293-7073.

\section{Introduction}

In addition if you would like to discuss problems, concerns, have suggestions related to research, or would like to offer input about the research, contact the Office of Research Integrity and Compliance at 304-

\section{Page}

1 of 8 
Initials Date

Tracking \#: $\quad$ H-23586

293-7073.

You, , have been asked to participate in this research study, which has been explained to you by

This study is being conducted by Dr. Jean McCrory and Dr. Krystal Thomas in the Department of Human Performance and Applied Exercise Science at West Virginia University.

\section{Purposes of the Study}

The purpose of this study is to learn more about how foot and leg alignment changes over the course of a pregnancy and how those changes are related to foot, leg, and low back pain. WVU expects to enroll approximately 100 subjects (50 pregnant and 50 nonpregnant).

\section{Description of Procedures}

This study involves us taking measurements on your foot and leg and you answering a series of questionnaires about foot, leg, and low back pain. If you are pregnant, we will ask you to come in to the study during each of your trimesters and one month post-partum. If you are not pregnant, this will be your only study visit. Each visit will take approximately 30 minutes for you to complete. You will be asked to fill out a questionnaire regarding foot, leg, and low back pain. This will take approximately 10 minutes. You do not have to answer all the questions. You will have the opportunity to see the questionnaire before signing this consent form.

We will ask you to be barefoot so that we can take good measurements of your feet. We will also ask you to wear a close fitting pair of shorts. We will provide you with a pair to wear during testing if you did not bring a pair with you. You can wear any shirt that you like.

Because we would like to study how your foot and leg position may be related to any pain you may feel in your foot, leg, and lower back, we will give you a questionnaire which asks you to rate any discomfort that you may be experiencing.

We will measure your height and weight using a standard medical scale. Next, we are going to make a series of measurements about the shape of

\section{Page}

2 of 8 
Initials Date

Tracking \#: $\quad$ H-23586

your foot and the alignment of your ankles and pelvis. We will make measurements of both of your feet. The side we test first (left or right) will be randomly chosen.

Because we think pregnancy may affect the length and width of your foot, we will use a caliper, which is similar to a ruler, to measure the length and width of your foot.

We also believe that pregnancy may change the shape of the arch of your foot. We will ask you to step on a special inkpad to get a footprint of your foot. This inkpad has a piece of rubber on it that goes between your foot and the ink, so you will not get any ink of your foot. We also will take a photograph of your foot when you are sitting and when you are standing. We will stick a silver reflective sticker on your foot for the photograph. The sticker is made for use on skin. Your name will not appear in the photograph. From these photographs, we are going to measure the height of your instep (the top of your foot above your arch). We are also going to measure how much your arch may drop when you put weight on your foot. Finally, we are going to measure the height of the arch of your foot using a set of sliding calipers made for this purpose.

Next, we are going to measure the angle that your foot makes with your leg. We will ask you to kneel on a chair so we can put two reflective stickers on the back of your foot.

We will also put two stickers on the back of your calf. We will ask you to stand with your feet shoulder width apart, and we will take a picture of the back of your legs.

Finally, we will put two reflective stickers on the front of your hips. We will take a picture of you standing in a relaxed position with your feet shoulder width apart. This will give us the angle that your pelvis makes with the horizontal, so we can tell if your pelvis is tilted to one side or the other.

We want to assess how much the weight gain that accompanies pregnancy may affect the shape of your foot. Therefore, we will also make all of the above measurements with you wearing a weighted pack on your front. The amount of weight will be the estimated amount that you have yet to gain in

\section{Page}

3 of 8

Initials Date 
Tracking \#: $\quad$ H-23586

your pregnancy. The average woman gains 32 pounds while pregnant. If you have already gained 32 pounds, then we will not add any weight. If you are not pregnant, we will add 32 pounds.

In total, we will take seven pictures without wearing the weighted backpack: two of each foot, one of the back of each leg, and one of your pelvis. And we will take seven with you wearing the weighted front pack.

Your face will not be included in any of the pictures. The participation in this study will remain confidential and we will not have any pictures that identify you as a participant in the study.

\section{Risks and Discomforts}

There are no known or expected risks from participating in this study, except for the mild frustration associated with answering the questions.

\section{Alternatives}

You do not have to participate in this study.

The only alternative to participating in this study is not participating in this study.

\section{Benefits}

You may not receive any direct benefit from this study. The knowledge gained from this study may eventually benefit others.

\section{Financial Considerations}

You will not incur any costs from participating in this research study.

\section{Confidentiality}

Any information about you that is obtained as a result of your participation in this research will be kept as confidential as legally possible. Your research records, just like hospital records, may be subpoenaed by court order or may be inspected by federal regulatory authorities without your additional consent.

\section{Page}

4 of 8 
Initials Date

Tracking \#: $\quad$ H-23586

Photographs will be kept locked up and will be destroyed as soon as possible after the research is finished. Your name will not appear on the photographs

In any publications that result from this research, neither your name nor any information from which you might be identified will be published without your consent.

We know that information about you and your health is private. We are dedicated to protecting the privacy of that information. Because of this promise, we must get your written authorization (permission) before we may use or disclose your protected health information or share it with others for research purposes.

You can decide to sign or not to sign this authorization section. However, if you choose not to sign this authorization, you will not be able to take part

in the research study. Whatever choice you make about this research study, it will not have an effect on your access to medical care.

\section{Persons/Organizations providing the information:}

Patient/West Virginia University Hospitals

\section{Persons/Organizations receiving the information:}

- The research site(s) carrying out this study. This includes UHA or UHA Affiliated, WVU, WVU Hospitals. It also includes each site's research staff and medical staff.

- Health care providers who provide services to you as part of this research study.

- Laboratories and other people and groups that look into your health information as part of this study in agreement with the study protocol.

- The United States Department of Health and Human Services (which includes the National Institutes of Health, Food and Drug Administration (FDA)) and other groups that have the right to use 
Page

5 of 8

Initials Date

Tracking \#: $\quad$ H-23586

the information as required by law.

- The members and staff of any Institutional Review Board (IRB) that oversees this research study.

- West Virginia University Office of Research Compliance and Office of Sponsored Programs.

- West Virginia University Clinical Trials Research Unit.

The following information will be used:

Information from your existing medical records and new information about you that is created or collected during the study such as: height, weight, lower body measurements, demographic data, and study forms.

\section{The information is being disclosed for the following reasons:}

- Review of your data for quality assurance purposes

- Publication of study results (without identifying you)

- Other research purposes such as evaluating other products or therapies for patients; developing a better understanding of pregnancy; improving the design of future clinical trials

\section{You may cancel this authorization at any time by writing to the Principal Investigator:}

Jean L. McCrory, PhD, 8315 HSC South, PO Box 9227,

Morgantown, WV 26506-9227;

email: jlmccrory@hsc.wvu.edu

If you cancel this authorization, any information that was collected already for this study cannot be withdrawn. Once information is disclosed, according to this authorization the recipient may redisclose it and then the information may no longer be protected by federal privacy regulations.

Page 
6 of 8

Initials Date

Tracking \#: $\quad$ H-23586

You have a right to see and make copies of your medical records. You will not be able to see or copy your records related to the study until the sponsor has completed all work related to the study. At that time you may ask to see the study doctor's files related to your

participation in the study and have the study doctor correct any information about you that is wrong.

This authorization will not expire unless you cancel it. (or has a specific expiration date)

\section{Voluntary Participation}

Participation in this study is voluntary. You are free to withdraw your consent to participate in this study at any time, by contacting Dr. McCrory at:

Jean McCrory, PhD Exercise Physiology PO Box 9227

Morgantown, WV, 26506-9227

Refusal to participate or withdrawal will not affect your future care, [or your employee status at West Virginia University or your class standing or grades, as appropriate] and will involve no penalty to you. In the event new information becomes available that may affect your willingness to participate in this study, this information will be given to you so that you can make an informed decision about whether or not to continue your participation. You have been given the opportunity to ask questions about the research, and you have received answers concerning areas you did not understand.
Page
7 of 8
Initials Date 
Tracking \#: $\quad$ H-23586

Upon signing this form, you will receive a copy.

I willingly consent to participate in this research.

Signature of Subject or Printed Name

Date Time

Subjects Legal Representative

The participant has had the opportunity to have questions addressed. The participant willingly agrees to be in the study.

Signature of Investigator or Printed Name

Date Time

Co-Investigator

Page

8 of 8

Initials Date 


\section{APPENDIX C: Pregnancy and Foot Study: Lower Extremity Pain Visual $\underline{\text { Analogue Scale }}$}

On the following pages is a questionnaire with questions related to lower body problems (eg. Pain). These include the lower back, hip/buttocks, upper leg, knee, lower leg and foot/ankle. To answer the questions a scale is available in the form of a line. Please mark the appropriate point on the line with a cross, which describes best your personal situation. At the very left side of the line is the most negative value, at the very right the most positive. Please use only marks, do not write text.

This is an example for an answer of the question "How are you today?" as shown:

Very bad
Excellent, very well

The answer at the cross on the line means in this example that you feel "well", however not "very well".

You do not have to answer each question! Answer only the questions which you would like and which you have understood! Please use the field "additions/characeristics/remarks" for suggestions for improvement and/or criticism.

\section{Explanation of some terms:}

Physical rest: This means that you do not do arduous things, i.e. you are reading a paper, lying on the sofa or in a bed, watching television etc.

Physical activity: This means that you are performing physically demanding activities, i.e. arduous garden work, occupational work, sport etc.

Activities of daily life: Personal activities such as getting out of bed, eating, washing yourself, getting dressed, tying your shoes etc.

\section{Additions / remarks}


LOWER BACK

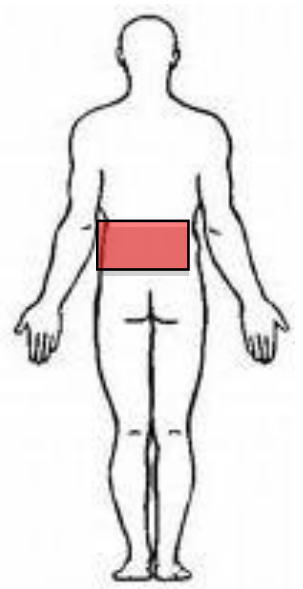

How much does lower back pain affect your gait?

Strong limping

Never, very

rarely

How often do you have lower back pain in physical rest?

Constantly,

always

Never, very rarely

How intense is this back pain in physical rest?

Extreme pain

No pain

How often do you have lower back pain during physical activity?

Constantly, always

Never, very rarely

How strong is this lower back pain during physical activity?

Strong limping

Never, very rarely

How much do lower back problems affect your daily activities (eg. getting dressed, eating, washing, etc. )?

Impossible on

my own, need

constant help

No limitation

climbing

stairs 


\section{HIP/BUTTOCKS}

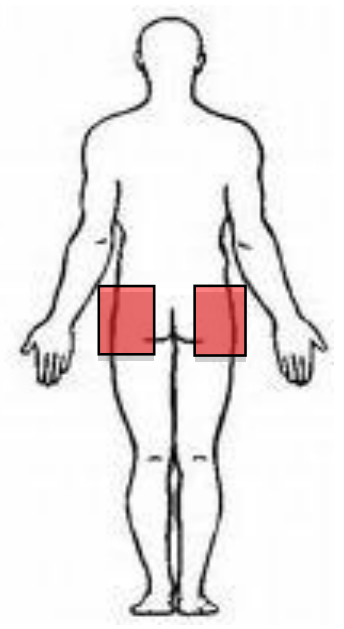

How much does hip/buttocks pain affect your gait?

Strong limping

Never, very

rarely

How often do you have hip/buttocks pain in physical rest?

Constantly,

always

How intense is this hip/buttocks in physical rest?

Extreme pain

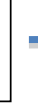

No pain

Never, very rarely

How often do you have hip/buttocks pain during physical activity?

Constantly, always
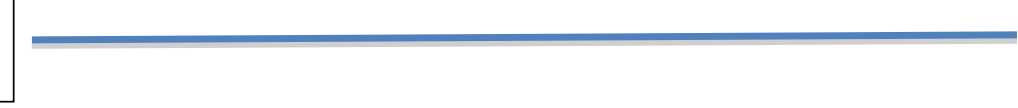

Never, very rarely

How strong is this hip/buttocks pain during physical activity?

Strong limping

Never, very rarely

How much do hip/buttocks problems affect your daily activities (eg. getting dressed, eating, washing, etc. )?

Impossible on

my own, need

constant help

No limitation

climbing

stairs 


\section{UPPER LEG}

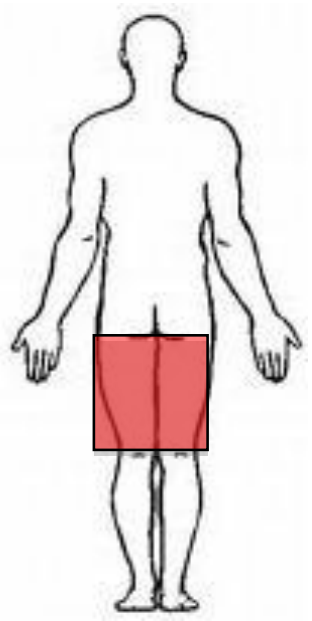

How much does upper leg pain affect your gait?

Strong limping

Never, very rarely

How often do you have upper leg pain in physical rest?

Constantly, always

Never, very rarely

How intense is this upper leg in physical rest?

Extreme pain

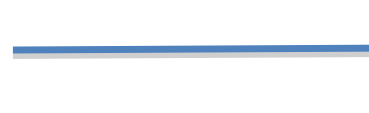

No pain

How often do you have upper leg pain during physical activity?

Constantly, always

Never, very rarely

How strong is this upper leg pain during physical activity?

Strong limping

Never, very rarely

How much do upper leg problems affect your daily activities (eg. getting dressed, eating, washing, etc. )? 


\section{KNEE}
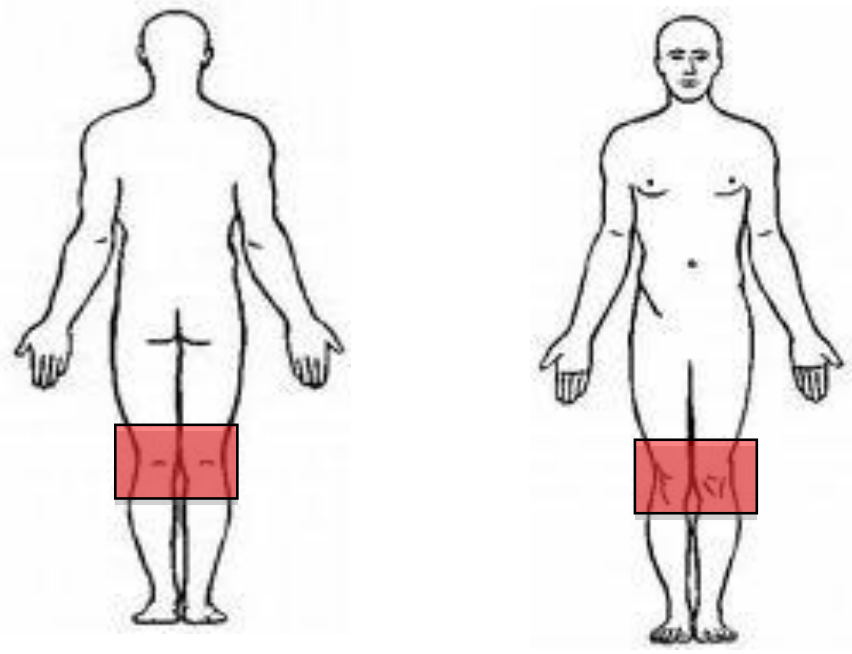

How much does knee pain affect your gait?

Strong limping

Never, very rarely

How often do you have knee pain in physical rest?

Constantly, always

Never, very rarely

How intense is this knee in physical rest?

Extreme pain

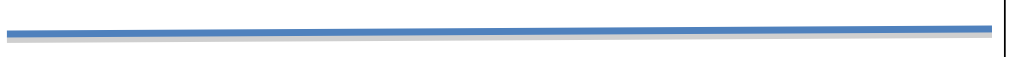

No pain

How often do you have knee pain during physical activity?

Constantly,

always

Never, very

rarely

How strong is this knee pain during physical activity?

Strong limping

Never, very

rarely

How much do knee problems affect your daily activities (eg. getting dressed, eating, washing, etc. )? 


\section{LOWER LEG}

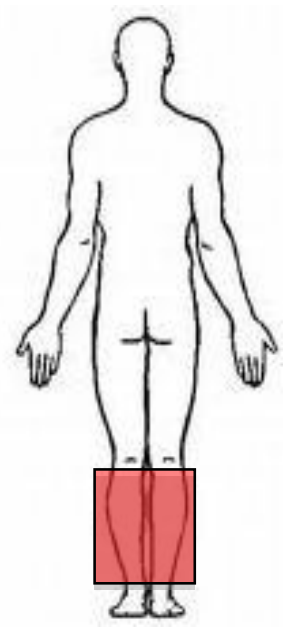

How much does lower leg pain affect your gait?

Strong limping

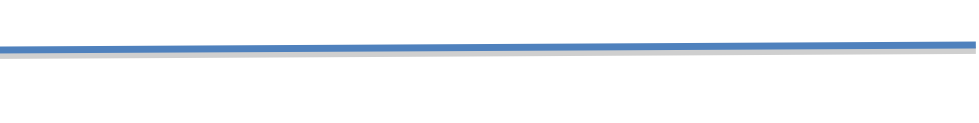

Never, very rarely

How often do you have lower leg pain in physical rest?

Constantly,

always

Never, very

rarely

How intense is this lower leg in physical rest?

Extreme pain

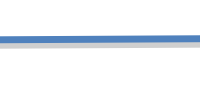

How often do you have lower leg pain during physical activity?

Constantly,

always

How strong is this lower leg pain during physical activity?
No pain

Never, very rarely

Never, very

rarely

How much do lower leg problems affect your daily activities (eg. getting dressed, eating, washing, etc. )? 


\section{FOOT/ANKLE}

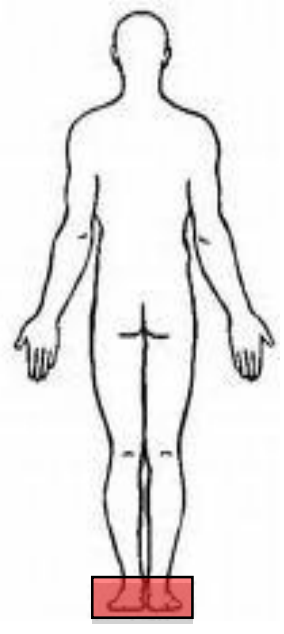

How much does foot/ankle pain affect your gait?

Strong limping

Never, very rarely

How often do you have foot/ankle pain in physical rest?

Constantly,

always

Never, very rarely

How intense is this foot/ankle in physical rest?
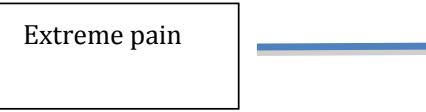

No pain

How often do you have foot/ankle pain during physical activity?

Constantly,

always

Never, very

rarely

How strong is this foot/ankle pain during physical activity?

Strong limping

Never, very rarely

How much do foot/ankle problems affect your daily activities (eg. getting dressed, eating, washing, etc. )? 